Board of Governors of the Federal Reserve System

International Finance Discussion Papers

Number 539

February 1996

\title{
COMPARING THE WELFARE COSTS AND THE INITIAL DYNAMICS OF ALTERNATIVE TEMPORARY STABILIZATION POLICIES
}

\author{
Martin Uribe
}

NOTE: International Finance Discussion Papers are preliminary materials circulated to stimulate discussion and critical comment. References in publications to International Finance Discussion Papers (other than an acknowledgment that the writer has had access to unpublished material) should be cleareu with the author or authors. 


\begin{abstract}
This paper compares the welfare costs and initial dynamics of three alternative inflation stabilization policies using the staggered price model with imperfect credibility and currency substitution developed by Calvo and Végh (1990). In addition to the policies analyzed by Calvo and Végh (1990) - a temporary exchange-rate based stabilization program (ERB), and a temporary money based program (MB) - this paper considers a third stabilization policy consisting of a temporary money based program with initial reliquefication -i.e., an initial once-and-for-all increase in the money supply- that keeps the nominal and real exchange rate from appreciating on impact (MBR). Simulation results suggest that the welfare costs associated with ERB and MBR programs are lower than those generated by $\mathrm{MB}$ programs. This seems to be the case even for highly temporary programs and for economies with low degree of currency substitution. ERB and MBR programs produce similar welfare costs except in two cases: when the policy change is very temporary, MBR programs do better. while for high values of the elasticity of currency substitution ERB programs outperform MBR programs.
\end{abstract}




\title{
Comparing the Welfare Costs and the Initial Dynamics of Alternative Temporary Stabilization Policies
}

\author{
Martín Uribe*
}

\section{Introduction}

A long debate in open economy macroeconomic policy is concerned with the issue of identifying the best nominal anchor for stopping high inflation. Two of the most popular instruments generally discussed are the money supply and the nominal exchange rate. One of the reasons for this long lasting discussion might be found in empirical evidence suggesting that exchange-rate based programs are associated with an initial boom in aggregate consumption and an eventual recession, whereas in money based programs the recession is born right at the outset, so it is unclear which strategy is the less costly. ${ }^{1}$

This paper addresses this issue by performing welfare comparisons in the basic analytical framework developed by Calvo and Végh (1990). The reason for choosing this framework is that it succeeds in reproducing the "recession now versus recession later" empirical regularity, together with several other stylized facts associated with exchange-rate based and money based stabilization programs. Four elements of the Calvo-Végh model are important in replicating these stylized facts: (1) inflation acts as a tax on consumption via a cash-inadvance constraint, (2) currency substitution, (3) staggered price setting in the home-good market a la (alvo (1983) and (4) the temporariness hypothesis, by which agents perceive the stabilization programs as lasting for only a finite period of time.

-The author is an Economist at the Division of Internationa! :"inance, Board of Governors of the Federal Reserve System. I would like to thank Guillermo Mondino, Jorge Roldós, Stephanie Schmitt-Grohé, Carlos Végh, Michael Woodford and seminar participants at the IMF for helpful comments. This paper represents the views of the author and should not be interpreted as reflecting the views of the Board of Governors of the Federal Reserve System or other members of its staff. Address for correspondence: International Finance Division. Stop 24. Board of Governors of the Federal Reserve System, Washington DC 20551, (20: ij2 3780 , email uribem@ifrb.gov.

${ }^{1} \mathrm{~A}$ recent account of these empirical regularities is provided by Calvo and Végh (1993a). 
This paper evaluates three different types of stabilization policies: a temporary reduction in the devaluation rate, a temporary reduction in the money growth rate, and a temporary reduction in the money growth rate accompanied by an initial increase in the money supply that keeps the nominal exchange rate from appreciating on impact. This last policy, which is frequently advocated by policymakers, as a way to avoid high interest rates and recession during the initial phase of inflation stabilization programs, has not been formally analyzed in the literature on temporary stabilization. This policy will be referred to as a money based program with initial reliquefication.

The next section presents the Calvo-Végh model, emphasizing the method used for computing dynamics and welfare costs. Particular functional forms are assumed for preferences and technologies. Following Calvo and Végh (1990), the instantaneous utility function is assumed to be additively separable in home and traded goods and logarithmic in each of the two goods. Thus, the welfare comparisons are restricted to the case of a unitary intertemporal elasticity of substitution. This assumption was made here for computational convenience but is certainly a limitation, (see section 7 for more discussion on this). The liquidity technology is assumed to be of the CES type in domestic and foreign currency. The

supply of traded goods is assumed to be exogenously given, while output in the nontraded good sector is assumed to be demand determined.

Sections 3 to 5 are devoted to comparing the initial dynamics of the model under the three alternative stabilization policies described above. Section 6 describes the welfare criteria used to compare the alternative stabilization policies and performs welfare comparisons for different parameter values. Section 7 closes the paper with some remarks.

\section{Solving the Calvo and Végh (1990) Model}

This section presents a closed form solution to the Calvo-Végh (1990) model under exchangerate based programs and exact numerical solutions for money based and money based with initial reliquefication programs (see Calvo and Végh, 1990 for a diagrammatic exposition of exchange-rate based and money based programs). The main features of the model are staggered prices in the nontraded sector a la Calvo (1983), currency substitution, and imperfect credibility about monetary policy.

\subsection{Households}

Consider an economy populated by a large number of identical households with preferences defined over paths of consumption of traded goods, $c_{t}^{*}$, and non-traded goods, $c_{t}$, and de- 
scribed by the following utility function.

$$
\int_{0}^{\infty} e^{-\beta t}\left[\ln \left(c_{t}^{*}\right)+\ln \left(c_{t}\right)\right] d t
$$

where $\beta>0$ denotes the subjective discount factor.

Households are assumed to have access to three assets. Domestic currency, $m_{t}^{d}$, foreign currency, $f_{t}$, and a foreign-currency denominated bond, $b_{t}^{h}$, that pays the constant interest rate $r$ in foreign currency. These three variables are expressed in terms of traded goods. The budget constraint of the household is given by ${ }^{2}$

$$
\int_{0}^{\infty} e^{-r t}\left[c_{t}^{*}+c_{t} / \epsilon_{t}+\left(\epsilon_{t}+r\right) m_{t}^{d}+r f_{t}\right] d t=m_{0}^{d}+f_{0}+b_{0}+\int_{0}^{\infty} e^{-r t}\left(y_{t}^{*}+y_{t} / e_{t}+\tau_{t}\right) d t
$$

where $\epsilon_{t}$ denotes the devaluation rate, $e_{t}$ denotes the real exchange rate (i.e., the relative price of the traded good in terms of home goods), $y_{t}^{*}$ and $y_{t}$ denote the household's income of traded and home goods respectively, and $\tau_{t}$ denotes a lump-sum transfer received from the government, expressed in terms of the foreign currency. The foreign-currency price of the traded good is assumed to be equal to one. Households can use domestic and foreign currency to purchase goods. These transactions are assumed to be subject to a cash-inadvance constraint of the form

$$
L\left(m_{t}^{d}, f_{t}\right) \geq \alpha\left(c_{t}^{*}+c_{t} / e_{t}\right)
$$

where $a>0$ and $L(\cdot \cdot \cdot)$ is a CES function with elasticity of substitution $(1+\rho)^{-1}>0$ and share parameter $0<\gamma \leq 1$. that is.

$$
L(m, f) \equiv\left[\gamma m^{-\rho}+(1-\gamma) f^{-\rho}\right]^{-1 / \rho}
$$

The household's problem consists in choosing paths for consumption and asset holdings so as to maximize (1) subject to (2) and (3). For simplicity, it is assumed that $\beta=r$. The first order conditions corresponding to this problem are

$$
\frac{1}{c_{t}^{*}}=\lambda\left[1+\alpha \frac{\epsilon_{t}+r}{L_{m}\left(m_{t}^{d}, f_{t}\right)}\right]
$$

\footnotetext{
${ }^{2}$ Implicit in this budget constraint are a borrowing constraint of the type $\lim _{t \rightarrow \infty} e^{-r t}\left(b_{t}+f_{t}+m_{t}^{d}\right) \geq 0$ imposed on households and the continuity of the time path of $b_{t}+f_{t}+m_{t}^{d}$, which will hold in $a^{11}$ the experiments studied below.
} 


$$
\begin{gathered}
\frac{c_{t}}{c_{t}^{*}}=e_{t} \\
\frac{L_{m}\left(m_{t}^{d}, f_{t}\right)}{L_{f}\left(m_{t}^{d}, f_{t}\right)}=\frac{\epsilon_{t}+r}{r}
\end{gathered}
$$

where $\lambda$ is a Lagrange multiplier associated with the budget constraint (2). It follows from (7) and from the fact that the liquidity function is linearly homogeneous, that the ratio of foreign to domestic currency depends only on $\epsilon_{t}$.

\section{$2.2 \quad$ Aggregate supply}

It is assumed that the path of the price level of home goods is continuous but that its growth rate can "jump"; moreover, its right-hand time-derivative is assumed to be proportional to the log-difference between "full-employment" and current output, that is,

$$
\dot{\pi}_{t}=-\theta \ln \left(y_{t} / \bar{y}\right)
$$

where $\pi_{t}$ denotes the inflation rate of home goods, $\bar{y}$ denotes full-employment output and $\theta$ is a positive parameter. The dot on $\pi_{t}$ denotes its right-hand time-derivative. This specification follows the model of staggered price setting developed by Calvo (1983). We assume that $\dot{\pi}_{t}$ is proportional to the log-difference, rather than to the difference between potential and current output. This slight departure from Calvo (1983) and Calvo and Végh $(1990,1993 b)$ makes it possible to obtain a closed form solution of the model in the case of a temporary exchange-rate based stabilization program. Importantly, the modification does not violate any of the original framework's micro-foundations. ${ }^{3}$

\subsection{The government}

The government is assumed to perform lump-sum transfers, $\tau_{t}$, to the public, to hold foreigncurrency denominated bonds, $b_{t}^{g}$, and to be allowed to print domestic currency. The money supply, expressed in terms of traded goods, is denoted by $m_{t}$. The right- hand time-derivative of $b_{t}$ is given by

$$
\dot{b}_{t}^{g}=\mu_{t} m_{t}^{s}+r b_{t}^{g}-\tau_{t}
$$

\footnotetext{
${ }^{3}$ Formally, the derivation of the expression $\dot{\pi}_{t}=-\theta E_{t}$, where $E_{t}$ is some measure of aggregate excess demand is independent of the actual functional form assumed for $E_{t}$ (see Calvo, 1983, pp. 385-387).
} 
where $\mu_{t}$ denotes the right-hand growth rate of the nominal money supply. The right-hand time derivative of real balances is in turn given by,

$$
\dot{m}_{t}^{s}=m_{t}^{s}\left(\mu_{t}-\epsilon_{t}\right)
$$

Combining these last two expressions, one can express the present-value budp $t$ constraint of the government $\mathrm{as}^{4}$

$$
b_{0}^{g}-m_{0}^{s}=\int_{0}^{\infty} e^{-r t}\left[\tau_{t}-\left(r+\epsilon_{t}\right) m_{t}^{s}\right] d t
$$

where $b_{0}^{g}-m_{0}^{g}$ is taken as given by the government.

\subsection{Equilibrium}

In equilibrium, the home-good market clears and the money supply equals money demand, that is

$$
\begin{gathered}
y_{t}=c_{t} \\
m_{t}^{s}=m_{t}^{d}
\end{gathered}
$$

It is also assumed perfect capital mobility, so the domestic nominal interest rate, $i_{t}$, is given by

$$
i_{t}=r+\epsilon_{t}
$$

Combining (2). (10), (11) and (12) gives

$$
r \int_{0}^{\infty} \epsilon^{-r t}\left(c_{t}^{*}+r f_{t}\right) d t=y^{p}
$$

where $y^{p}$ denotes permanent income and is given by

$$
y^{p} \equiv r\left(b_{0}+b_{0}^{g}+f_{0}\right)+r \int_{0}^{\infty} e^{-r t} y_{t}^{*} d t
$$

The (right-hand) growth rate of the real exchange rate, is given by the difference between the devaluation rate and the home-good inflation rate, that is,

$$
\dot{\epsilon}_{t}=\epsilon_{t}\left(\epsilon_{t}-\pi_{t}\right)
$$

Using the CES form for liquidity services assumed in (4), the ratio of foreign to domestic

\footnotetext{
${ }^{4}$ As in the household's problem, it is implicitly assumed that the government is subject to a borrowing constraint of the type $\lim _{t \rightarrow \infty} e^{-r t}\left(b_{t}^{g}-m_{t}^{s}\right)=0$ and that the time path of $b_{t}^{g}-m_{t}^{s}$ is continuous.
} 
currency can be written as

$$
\frac{f_{t}}{m_{t}}=\left[\left(\frac{1-\gamma}{\gamma}\right)\left(\frac{i_{t}}{r}\right)\right]^{\frac{1}{1+\rho}} \equiv w\left(i_{t}\right) \quad \text { with } w^{\prime}(i)>0
$$

Combining (5), (13), and (17), $c_{t}^{*}$ can be expressed as a function of the nominal interest rate and of the Lagrange multiplier,

$$
c_{t}^{*}=\lambda^{-1} \frac{\gamma L\left(1, w\left(i_{t}\right)\right)^{1+\rho}}{\gamma L\left(1, w\left(i_{t}\right)\right)^{1+\rho}+\alpha i_{t}} \equiv \lambda^{-1} z\left(i_{t}\right)
$$

with $z^{\prime}(i)>0$. Using $(3),(4),(6),(17)$ and $(18)$ one can write $f_{t}$ as,

$$
f_{t}=\lambda^{-1} \frac{2 \alpha w\left(i_{t}\right) z\left(i_{t}\right)}{L\left(1, w\left(i_{t}\right)\right)}
$$

and combining (18) and (19),

$$
c_{t}^{*}+r f_{t}=\lambda^{-1} z\left(i_{t}\right)\left[1+\frac{2 r \alpha w\left(i_{t}\right)}{L\left(1, w\left(i_{t}\right)\right)}\right] \equiv \lambda^{-1} z\left(i_{t}\right) x\left(i_{t}\right)
$$

where $x^{\prime}\left(i_{t}\right) \geq 0$. Using $(20)$ and the economy's resource constraint (14), one can then solve for the value of the Lagrange multiplier $\lambda$, as a function of the time path of the nominal interest rate and of the permanent income,

$$
\lambda=\frac{r}{y^{p}} \int_{0}^{\infty} e^{-r t} z\left(i_{t}\right) x\left(i_{t}\right) d t
$$

\subsection{Initial conditions}

Suppose that previous to the announcement of the stabilization program $(t<0)$, the economy is in a steady-state in which both the devaluation and the inflation rates are constant. Suppose also that in this steady state the devaluation rate is $\epsilon^{H}$. The nomirial interest rate is then also constant at $i^{H}=r+e^{H}$. From (21) the pre-stabilization value of $\lambda$ is $\lambda_{-}=z\left(i^{H}\right) x\left(i^{H}\right) / y^{p}$ (the subscript "." denotes pre-stabilization values), and using this in (18), the consumption of tradables is $c_{-}^{*}=y^{p} / x\left(i^{H}\right)$. Since the inflation rate is constant, equation (8) implies that consumption (and production) of home goods is at full-employment, $c_{-}=\bar{y}$. It then follows from the constancy of the consumption of traded and home goods that the real exchange rate is also constant at $e_{-}=\bar{y} x\left(i^{H}\right) / y^{p}$. Finally, from (16) the pre-stabilization inflation rate is $\pi_{-}=\epsilon^{H}$. 


\section{Temporary exchange-rate based stabilization}

The purpose of this section is to use the model described above, in order to numerically simulate its response to a temporary exchange-rate based inflation stabilization program. This simulations will later be compared to those arising from money-based stabilization programs. It turns out that for exchange-rate based stabilization programs, the functional forms assumed for preferences and technologies, allow us to obtain a close form solution of the model. ${ }^{5}$ As it will be shown below, this is not the case under money-based stabilization.

Suppose that at time $t=0$, the government unexpectedly announces a stabilization plan that lowers the devaluation rate from $\epsilon^{H}$ to $\epsilon^{L}$ for $T$ periods, that is,

$$
\epsilon_{t}= \begin{cases}\epsilon^{L} & \text { for } 0 \leq t<T \\ \epsilon^{H} & \text { for } t \geq T\end{cases}
$$

Suppose also that the government guarantees free convertibility of the domestic currency. It follows from (13) that the nominal interest rate is then given by

$$
i_{t}= \begin{cases}i^{L} \equiv \epsilon^{L}+r & \text { for } 0 \leq t<T \\ i^{H} \equiv \epsilon^{H}+r & \text { for } t \geq T\end{cases}
$$

The marginal utility of wealth, $\lambda$, can then be obtained by substituting this expression into equation (21),

$$
\lambda=\frac{1}{y^{p}}\left[\left(1-\epsilon^{-r T}\right) z\left(i^{L}\right) x\left(i^{L}\right)+\epsilon^{-r T} z\left(i^{H}\right) x\left(i^{H}\right)\right]
$$

It is not clear what the "announcement effect" on $\lambda$ is. When domestic currency is the sole means of exchange available in the economy $(\gamma=1)$, it follows from $(20)$ that $x\left(i_{t}\right)=1$, so $\lambda$ becomes a weighted average of $z\left(i^{H}\right) / y^{p}$ and $z\left(i^{L}\right) / y^{p}$, which, given that $z^{\prime}\left(i_{t}\right)<0$, is greater than the pre-announcement value $z\left(i^{H}\right) / y^{p}{ }^{6}$ Under currency substitution, on the other hand, $x^{\prime}\left(i_{t}\right)>0$, so the product $z\left(i_{t}\right) x\left(i_{t}\right)$ can be increasing or decreasing in $i_{t}$. If it was increasing in $i_{t}$. then $\lambda$ would decrease with the announcement of the stabilization program (this case is naturally more likely the larger is the elasticity of currency substitut.on).

\footnotetext{
${ }^{5}$ In the case in which domestic and foreign currency are used in fixed proportion $(\rho \rightarrow \infty$ in (4)) or when only domestic currency can be used to purchase goods $(\gamma=1)$, close form solutions are still easy to obtain under a slightly more general class of preferences; specifically, the class of separable CRRA instant utility functions.

${ }^{6}$ This result holds also when the elasticity of currency substitution is zero. In this case $w\left(i_{t}\right)$ is not zero but constant.
} 
The time path of tradables is a step function of the form

$$
c_{t}^{*}= \begin{cases}\lambda^{-1} z\left(i^{L}\right) & \text { for } 0 \leq t<T \\ \lambda^{-1} z\left(i^{H}\right) & \text { for } t \geq T\end{cases}
$$

Two things are apparent from this expression. First, the program generates an initial boom in the consumption of tradables ${ }^{7}$ Also, since the supply of traded goods is assumed to be constant, the trade balance deteriorates on impact. These two features are consistent with the stylized facts associated with this type of programs, see Végh (1992) and Kiguel and Liviatan (1992a) $)^{8}$ At $t=T c_{t}^{*}$ jumps down to its long-run steady state level, which can be lower or higher than the pre-stabilization level (see below).

\subsection{Steady state}

Consider a long-run state of the economy, in which all real variables and inflation are constant. From (23), the steady state of consumption of tradables is reached at $\mathrm{T}$,

$$
c^{*}=c_{T}^{*}
$$

where variables without a time subscript refer to long-run values. From (8) and (11), in turn. the steady state of consumption of home goods is

$$
c=\bar{y}
$$

Using (6) one can express the long-run value of the real exchange rate as

$$
\epsilon=\bar{y} / c_{T}^{*}
$$

From (16), (22) and (23) the steady states of the devaluation rate, the nominal interest rate and the inflation rate are

$$
\epsilon=\epsilon^{H}
$$

\footnotetext{
${ }^{7}$ The ratio of $c_{0}^{*}$ over the pre-stabilization level $c_{-}^{*}$ is given by

$$
\frac{x\left(i^{H}\right) z\left(i^{L}\right)}{\left(1-e^{-r T}\right) x\left(i^{H}\right) z\left(i^{H}\right)+e^{-r T} x\left(i^{L}\right) z\left(i^{L}\right)}
$$

which is greater than one because $z^{\prime}(i)<0$ and $x^{\prime}(i)>0$.

"What is less consistent with the empirical regularities, is the precise shape of this boom-recessi-a-cycle in tradables. The data suggests an inverted-U-shaped path, rather than the step function described in (22).
} 


$$
\begin{gathered}
\pi=\epsilon^{H} \\
i=\epsilon^{H}+r
\end{gathered}
$$

\subsection{Dynamics}

In analyzing the initial dynamics of the model in response to a temporary reduction in the devaluation rate, it is convenient to express some of the variables of interest as deviations or log-deviations from their steady state levels. Define,

$$
\begin{aligned}
\Delta \epsilon_{t} & \equiv \ln \left(e_{t} / e\right) \\
\Delta c_{t} & \equiv \ln \left(c_{t} / \hat{y}\right) \\
\Delta c_{t}^{*} & \equiv \ln \left(c_{t}^{*} / c_{T}^{*}\right) \\
\Delta \pi_{t} & \equiv \pi_{t}-\epsilon^{H} \\
\Delta \epsilon_{t} & \equiv \epsilon_{t}-\epsilon^{H}
\end{aligned}
$$

It will also prove convenient to write $\Delta c_{t}^{*}$ and $\Delta \epsilon_{t}$ in the following way,

$$
\begin{aligned}
& \Delta c_{t}^{*}=\Delta c_{0}^{*}\left(1-u_{T}(t)\right) \\
& \Delta \epsilon_{t}=\Delta \epsilon_{0}\left(1-u_{T}(t)\right)
\end{aligned}
$$

where $u_{T}(t)$ denotes the unit step function, defined as,

$$
u_{T}(t)= \begin{cases}0 & \text { for } 0 \leq t<T \\ 1 & \text { for } t \geq T\end{cases}
$$

Using (6), one can express (8) and (16) as a system of two linear differential equations in $\Delta \pi_{t}$ and $\Delta \epsilon_{t}$.

$$
\begin{gathered}
{\left[\begin{array}{c}
\Delta \dot{\pi}_{t} \\
\Delta \dot{\epsilon}_{t}
\end{array}\right]=\left[\begin{array}{cc}
0 & -\phi^{2} \\
-1 & 0
\end{array}\right]\left[\begin{array}{c}
\Delta \pi_{t} \\
\Delta \epsilon_{t}
\end{array}\right]+\left[\begin{array}{c}
-\phi^{2} \Delta c_{0}^{*} \\
\Delta \epsilon_{0}
\end{array}\right]\left(1-u_{T}(t)\right)} \\
\text { where } \phi \equiv \sqrt{\theta}
\end{gathered}
$$

Since, given the policy rule, neither the price of the home good nor the nominal exchang rate can jump, the initial value of the real exchange rate is given by $\epsilon_{0}=e_{-}$and so $\Delta \epsilon_{0}=\ln \left(e_{-} / e\right)$. On the other hand. $\Delta \pi_{0}$ is chosen in such a way that $\pi_{t}$ is continuous for $t>0$ and converges 
to zero. ${ }^{9}$ An easy way to solve linear systems like (25) containing a non-linear forcing term, is described in Boyce and DiPrima (1965), and consists in applying the Laplace transform on it, solving the resulting algebraic linear system and applying the inverse Laplace transform operator to recover the original variables. Let $X(s)$ be the Laplace transform of $x_{t}$ evaluated at $s .{ }^{10}$ The Laplace transform of $(25)$ is then given by,

$$
s\left[\begin{array}{c}
\Delta \Pi(s) \\
\Delta E(s)
\end{array}\right]-\left[\begin{array}{c}
\Delta \pi_{0} \\
\Delta e_{0}
\end{array}\right]=\left[\begin{array}{cc}
0 & -\phi^{2} \\
-1 & 0
\end{array}\right]\left[\begin{array}{c}
\Delta \Pi(s) \\
\Delta E(s)
\end{array}\right]+\left[\begin{array}{c}
-\phi^{2} \Delta c_{0}^{*} \\
\Delta \epsilon_{0}
\end{array}\right] \frac{1-e^{-s T}}{s}
$$

Given $s$, this is an algebraic linear system in $[\Delta \Pi(s) \Delta E(s)]^{\prime}$ whose solution is given by

$$
\left[\begin{array}{c}
\Delta \Pi(s) \\
\Delta E(s)
\end{array}\right]=\frac{1}{s^{2}-\phi^{2}}\left[\begin{array}{cc}
s & -\phi^{2} \\
-1 & s
\end{array}\right]\left\{\left[\begin{array}{c}
-\phi^{2} \Delta c_{0}^{*} \\
\Delta \epsilon_{0}
\end{array}\right] \frac{1-e^{-s T}}{s}+\left[\begin{array}{c}
\Delta \pi_{0} \\
\Delta \epsilon_{0}
\end{array}\right]\right\}
$$

The original variables can be recovered by applying the inverse Laplace transform operator, to $(26),{ }^{11}$

Figures 1 and 2 show the transitional dynamics of some variables of interest in response to a temporary reduction in the devaluation rate $^{12}$ The baseline set of parameter values were chosen arbitrarily and are shown in table $1 .^{13}$ The time unit is a quarter. The economy starts in a steady state with an inflation rate of $10 \%\left(\epsilon^{H}=0.1\right)$ and the plan consists in setting the devaluation rate at $1 \%\left(\epsilon^{L}=0.01\right)$ for 10 quarters $(T=10) ; \epsilon_{t}$ then resumes

${ }^{9}$ The continuity of $\pi_{t}$ follows directly from the way in which equation (8) is derived in the staggered prices model. See Calvo (1983).

${ }^{10}$ The Laplace transform of $x_{t}$ is defined as,

$$
X(s) \equiv \int_{0}^{\infty} e^{-s t} x_{t} d t
$$

whenever this infinite integral converges. The Laplace transform is a linear operator and the transform of $\dot{x}_{t}$ is $s X(s)-x_{0}$. See for instance Boyce and DiPrima (1965) chapters 6 and 7 .

${ }^{11}$ Boyce and DiPrima (1965, page 226) provide a table of inverse Laplace transforms. The solution to (26) is given to by,

$$
\begin{aligned}
& \Delta \pi_{t}= \phi \Delta c_{0}^{*}\left[u_{T}(t) \sinh (\phi(t-T))-\sinh (\phi t)\right] \\
&+\Delta \epsilon_{0}\left[u_{T}(t) \cosh (\phi(t-T))-\cosh (\phi t)+1-u_{T}(t)\right] \\
&+\Delta \pi_{0} \cosh (\phi t)-\phi \Delta e_{0} \sinh (\phi t) \\
& \Delta \epsilon_{t}=-\Delta c_{0}^{*}\left[u_{T}(t) \cosh (\phi(t-T))-\cosh (\phi t)+1-u_{T}(t)\right] \\
&-\Delta \epsilon_{0} \phi^{-1}\left[u_{T}(t) \sinh (\phi(t-T))-\sinh (\phi t)\right] \\
&-\Delta \pi_{0} \phi^{-1} \sinh (\phi t)+\Delta e_{0} \cosh (\phi t) \\
& \text { with } \Delta \pi_{0}=\phi \Delta e_{0}+\left(1-e^{-\phi T}\right)\left(\phi \Delta c_{0}^{*}+\Delta \epsilon_{0}\right)
\end{aligned}
$$

where $\sinh (x) \equiv\left[e^{x}-e^{-x}\right] / 2$ and $\cosh (x) \equiv\left[e^{x}+e^{-x}\right] / 2$ denote the hyperbolic sine and co rac of $x$, respectively.

${ }^{12}$ The plots show levels, not deviations.

${ }^{13}$ The parameter values used in the simulation are always those shown in table 1 unless explicitly noted. 
to its original level of $10 \%$. Figure 1 shows the case in which only domestic currency can be used as a means of exchange $(\gamma=1)$. Qualitatively identical figures are shown in Calvo and Végh (1993b) and Végh (1992). The model captures the main empirical regularities of exchange-rate based stabilization episodes. Consumption of both goods display a boomrecession cycle, the real exchange rate appreciates and the trade balance deteriorates during the initial phase of the program.

Adding currency substitution does not change the qualitative response of the model. For high enough values of the elasticity of currency substitution, however, it might happen that the steady state consumption of tradables ends up being higher than its pre-stabilization level. This possibility arises because of the wealth effect associated with the substitution of domestic for foreign currency in response to the temporary reduction in the devaluation rate. This is shown in figure 2 . which displays the dynamics of consumption of tradables for $\gamma=.75$ and for two values of the elasticity of currency substitution, 1 and 2.5. The figure also shows the behavior of the ratio of domestic to foreign currency. Between $t=0$ and $t=T$, the increase in the demand for domestic currency is materialized via exchanging foreign for domestic currency at the central bank, who in turn invests them at the international interest rate and returns the proceeds to the public in a lump-sum fashion, generating the positive wealth effect mentioned above. This effect is obviously stronger the easier it is for the public to substitute currencies, i.e., the higher $1 /(1+\rho)$ is. The high-elasticity case is also associated with a steady state real exchange rate (not shown in the figure) lower than its pre-stabilization level. This follows from the fact that the steady state of consumption of home-goods is exogenously given and the real exchange rate equals the ratio of consumption of home goods to consumption of tradables.

In the next sections, the initial dynamics and welfare implications of this type of stabilization programs will be compared with money based stabilization programs.

\section{Temporary money based stabilization}

Consider now a stabilization program by which the government lowers the money growth rate from $\mu^{H}$ to $\mu^{L}<\mu^{H}$, for $T$ periods; that is,

$$
\mu_{t}= \begin{cases}\mu^{L} & \text { for } 0 \leq t<T \\ \mu^{H} & \text { for } t \geq T\end{cases}
$$

The nominal exchange rate and the devaluation rate are now endogenous variables.

As in the previous section, the emphasis will be put in the method used for computing 
the time paths of the variables of interest. In this case, however, it will not be possible to obtain close form solutions. Nevertheless, it will be shown that it is easy to compute numerical solutions using very standard routines.

Let us first derive the time paths of the nominal interest rate and domestic real balances. Using (3), (6), (17) and (18) one can write $m_{t}$ as

$$
m_{t}=\lambda^{-1} \frac{2 \alpha z\left(i_{t}\right)}{L\left(1, w\left(i_{t}\right)\right)} \equiv \lambda^{-1} v\left(i_{t}\right)
$$

where $v^{\prime}\left(i_{t}\right)<0$ because $z^{\prime}\left(i_{t}\right)<0$ and $w^{\prime}\left(i_{t}\right)>0$. Using this expression together with (12) and (13), one can write $(9)$ as, ${ }^{14}$

$$
\dot{i}_{t}=-\frac{v^{\prime}\left(i_{t}\right)}{v\left(i_{t}\right)}\left(i_{t}-\left(r+\mu_{t}\right)\right)
$$

since $-v^{\prime}(i) / v(i)$ is always positive, it follows from this expression and (27), that the unique non-explosive solution for $t \geq T$ is the steady state, that is

$$
i_{t}=r+\mu^{H} \quad \text { for } t \geq T
$$

For $0 \leq t<T$, the time path of $i_{t}$ can be found by solving the following initial value problem: Let $g_{t} \equiv i_{T-t}$; then the evolution of $g_{t}$ is governed by the following differential equation ${ }^{15}$

$$
\dot{g}_{i}=\frac{v^{\prime}\left(g_{t}\right)}{v\left(g_{t}\right)}\left(g_{t}-\left(r+\mu^{L}\right)\right)
$$

with $g(0)=r+\mu^{H}$. Numerical solutions to this equation can be easily (and quickly) obtained using any computer math package equipped with routines for solving initial value problems. ${ }^{16}$ In order to get the time paths of consumption of tradables and domestic and foreign real balances, it is necessary to first calculate the value of the multiplier $\lambda$ which, from (21), is

\footnotetext{
${ }^{14}$ When domestic and foreign currency are used in fixed proportions (i.e., $\rho \rightarrow \infty$ or $\gamma=1$ ), $m_{t}$ follows a linear first order differential equation that can be solved explicitly.

${ }^{15}$ This initial condition implicitly assumes that the nominal interest rate and real balances are continuous at $T$. If this was not the case, and given that the monetary policy implies that the nominal money supply is continuous at $T$, the nominal exchange rate would have to have a discontinuity at this point. This cannot be the case in a perfect foresight equilibrium because it would create an opportunity for unbounded arbitrage profits.

${ }^{16} \mathrm{All}$ simulations in this paper were done using the $M A T L A B$ subroutine $O D E 45$ which solves ordinary differential equations using fourth and fifth order Runge-Kutta formulas (see Boyce and DiPrima (1965), Chapter 8 for a description of this method). The subroutine's output gives the value of the function, aíuated at some points in the interval $0 \leq t \leq T$. To get values at any other $t$, one can use an interpolation subroutine. In this paper this was done using the MATLAB subroutine SPLINE which calculates data spline cubic interpolations.
} 
given by

$$
\lambda=\frac{r}{y^{p}} \int_{0}^{T} \epsilon^{-r T} z\left(i_{t}\right) x\left(i_{t}\right) d t+\frac{\epsilon^{-r T}}{y^{p}} z\left(r+\mu^{H}\right) x\left(r+\mu^{H}\right)
$$

The first term on the right hand side can be evaluated using a computer math package capable of solving integrals. ${ }^{17}$ Once $\lambda$ and the path of the nominal interest rate are computed, it is straight forward to obtain the paths of $c_{t}^{*}$ from (18), $f_{t}$ from (21), $m_{t}$ from (28) and $\epsilon_{t}$ from (13). Since these variables depend only on $\lambda$ and the contemporaneous nominal interest rate, they all reach their steady states at $t=T$. The dynamics of the real exchange rate and inflation are determined by a system similar to (25)

$$
\left[\begin{array}{c}
\Delta \dot{\pi}_{t} \\
\Delta \dot{\epsilon}_{t}
\end{array}\right]=\left[\begin{array}{cc}
0 & -\dot{\phi}^{2} \\
-1 & 0
\end{array}\right]\left[\begin{array}{c}
\Delta \pi_{t} \\
\Delta e_{t}
\end{array}\right]+\left[\begin{array}{c}
-\phi^{2} \Delta c_{t}^{*} \\
\Delta \epsilon_{t}
\end{array}\right]
$$

The difference between this system and (25) is that the forcing term is no longer a step function. The initial condition for $\Delta e_{t}$ is given by $\Delta e_{0}=\ln \left(\epsilon_{0} / \epsilon\right)$, where $e=\bar{y} / c_{T}^{*}$ is the steady state of the real exchange rate and $\epsilon_{0}$ is the initial value of the real exchange rate, which is no longer predetermined because the nominal exchange rate may jump at $t=0$. However. one can use the initial value of domestic real balances, whose path was already calculated, to determine $\epsilon_{0}$. Since given the policy rule neither the nominal money supply nor the price of the home good can jump at $t=0$, it follows that the following condition has to hold

$$
\epsilon_{0} m_{0}=\epsilon_{-} m
$$

where $\epsilon_{-}$and $m_{\text {- }}$ are the pre-stabilization values of the real exchange rate and of domestic real balances obtained above In order to calculate the initial value $\Delta \pi_{0} \equiv \pi_{0}-\left(r+\mu^{H}\right)$, it is convenient to define the following variable,

$$
h_{t} \equiv \Delta \pi_{t}-\phi \Delta \epsilon_{t}
$$

From (30) it follows that the evolution of $h_{t}$ is given by the following differential equation,

$$
\dot{h}_{t}=\phi h_{t}-\phi\left(\Delta \epsilon_{t}+\phi \Delta c_{t}^{*}\right)
$$

Since the forcing term of this equation is zero for $t \geq T$, and since $\phi>0$, the unique

\footnotetext{
${ }^{17}$ In this paper this was accomplished using the MATLAB subroutine $Q U A D 8$ which uses quad, it:ie methods to mumerically evaluate integrals.
} 
non-explosive solution for this equation satisfies $\dot{h}_{t}=0$ for $t \geq T$, or,

$$
\Delta \pi_{t}=\phi \Delta e_{t} \text { for } t \geq T
$$

The condition $h_{T}=0$ can then be used to write (32) as an initial value problem in exactly the same way as was done above with equation (29); the solution to this problem gives $h_{0}$, which in turn determines $\Delta \pi_{0}=h_{0}+\phi \Delta e_{0}$. Given $\Delta \pi_{0}$ and $\Delta e_{0},(30)$ becomes an initial value problem which can be solved numerically for $\Delta \pi_{t}$ and $\Delta e_{t}$ for $0 \leq t \leq T$. ${ }^{18}$ Condition (33) and the second equation in (30) then give the solution for $t \geq T$,

$$
\begin{aligned}
\Delta \epsilon_{t} & =\Delta e_{T} \epsilon^{-\phi(t-T)} \\
\Delta \pi_{t} & =\phi \Delta e_{T} e^{-\phi(t-T)}
\end{aligned}
$$

Figure 3 shows the transitional dynamics of a plan that reduces the money growth rate from $10 \%$ to $1 \%$ for 10 quarters for an economy that uses only domestic currency as a means of exchange $(\gamma=1)$. For comparison, the figure also includes the dynamics of an exchange-rate based program (the same shown in figure 1). The initial dynamics of the nominal interest rate are very similar in both type of programs and correspondingly, the paths of consumption of tradables also look alike. As $t$ approaches $T$, however, the nominal interest rate starts rising in the money based program. and this implies that the recession in the traded sector starts earlier for this type of plan. With respect to the consumption of home goods, the money based program does not induce an early boom but neither an early recession. In this singlecurrency economy, the consumption of home goods is proportional to real balances measured in terms of home goods, and since both the price level and the nominal mone: supply are predetermined at $t=0$. the consumption of home goods is also predetermined. This means that at $t=0$ the real exchange rate $\left(e_{0}=c_{0} / c_{0}^{*}\right)$ jumps down by the same proportion as $c_{0}^{*}$ does. This, in turn, can only happen if on impact the nominal exchange rate appreciates by that proportion. Finally, the domestic real interest rate is pretty flat during the whole stabilization period and takes off only after the plan is abandoned. Compare this with the initial period of low real interest rates in the exchange-rate based program.

Figure 4 shows the dynamics in an economy with currency substitution $(\gamma=.75)$. The differences between the two stabilization strategies are much more dramatic now. To start with, the consumption boom is much more pronounced under exchange-rate stabilization

\footnotetext{
${ }^{18}$ The $M A T L A B$ subroutine $O D E 45$ handles systems of ordinary differential equations as wel, as single differential equations. One can also calculate the path of $\Delta e_{t}$ rate by solving the single-equation initial value problem, $\Delta \dot{e}_{t}=-\phi \Delta e_{t}-h_{t}+\Delta \epsilon_{t}$.
} 
for two reasons: first the nominal interest rate is always lower under exchange-rate based stabilization than it is under money base stabilization, and second in the exchange-rate based stabilization program the wealth effect associated with the substitution of domestic for foreign currency when the devaluation rate falls induces higher consumption of tradables in both, the transition and the long run.

In the money based program, the higher demand for domestic currency materializes partly through a decrease in the nominal and real exchange rate on impact (recall that the price of home goods cannot jump). This discourages the consumption of home goods. So, while the exchange rate program is associated with an initial boom in this sector, the money based program generates an initial recession. The model then succeeds in replicating the empirical regularity of "recession now versus recession later". The initial recession in the money based program, in turn, is accompanied by deflation and high real interest rates during the initial phase of the plan, in contrast with what happens in the exchange rate based program in which the real interest rate is low throughout the transition.

\section{Temporary money based stabilization with initial reliq- uefication}

It is frequently argued that money based stabilization programs should be accompanied by an initial once-an-for-all increase in the money supply in order to avoid high real interest rates and recession. caused by the credit crunch associated with the initial increase in money demand. In this section reliquefication will adopt the form of an initial increase in the nominal money supply that keeps the nominal and real exchange rate from falling on impact. ${ }^{19}$

Technically, reliquefication means that the initial condition for the real exchange rate derived above (equation $(31))$ is now replaced by ${ }^{20}$

$$
\epsilon_{0}=\epsilon_{-}
$$

\footnotetext{
${ }^{19}$ The Peruvian stabilization program implemented by the Fujimori administration in August of 1990 is an example close to this type of policy. The plan consisted in a very strict fiscal and credit policy that virtually eliminated the monetization of fiscal deficits. In addition, the central bank engaged in purchases of foreign currency with the intention of sustaining the nominal exchange rate. See Kiguel and Liviatan (1992b) and Calvo and Végh (1993a) on this

${ }^{20}$ Since in this model it is assumed that the interest earned by the central bank on its reserves are returned to the public in a lump-sum fashion, it does not make any difference for the dynamics of the variables considered, whether the initial increase in the money supply is done through purchases of foreign cur ncy or through an helicopter-type transfer. Of course, these two methods are different from the stand point of the policymaker since they imply different paths for the stock of reserves held at the central bank.
} 
Figure 5 and 6 show the transitional dynamics implied by money based programs with and without initial reliquefication, as well as the initial dynamics of the exchange-rate based plan, in a single-currency economy (figure 5) and in one with currency substitution (figure $6)$. The last case is the most interesting because reliquefication has more evident effects, so only figure 6 will be discussed.

Let us first comment on the variables that are unaffected by reliquefication. The paths of real balances, consumption of tradables, and the nominal interest rate were derived independently of the initial value of the real exchange rate, so they are completely unaffected by reliquefication.

The effect of reliquefication on the rest of the variables, is to induce dynamics that look very similar to those arising from exchange-rate based programs during the initial phase of the plan and to money-based programs without reliquefication during the final phase of the program. For example, the money based program with initial reliquefication induces an initial boom in the consumption of home goods as does the exchange-rate based program, but only a mild recession by the time the program is abandoned, as is the case with the money based program without initial reliquefication. Something similar occurs with the behavior of the real interest rate: the money based program with initial reliquefication shares with the exchange rate program low rates in the initial phase but avoids the high rates induced by these plans by the time they are abandoned. The conclusions are similar for the real exchange rate and the inflation rate.

\section{Welfare comparisons of the different stabilization poli- cies}

This section compares the welfare implications of the three alternative temporary stabilization policies discussed above: exchange-rate based (ERB), money based (MB), and money based with initial reliquefication (MBR). These comparisons include sensitivity analysis aimed at highlighting which parameters of the model are important in determining the cost of each policy.

The measure of the welfare cost associated with each type of plan is defined as the fraction by which the pre-stabilization consumption streams of traded and home goods, $c_{-}^{*}$ and $c_{-}$have to be decreased in order to leave the consumer indifferent between consuming the decreased but constant path and the one arising from a given stabilization program. Formall $\because$ let $\xi$ 
denote the welfare cost. Then $\xi$ solves

$$
\ln \left(c_{-}^{*}\right)+\ln \left(c_{-}\right)+2 \ln ((1-\xi))=r \int_{0}^{\infty} e^{-r t}\left[\ln \left(c_{t}^{*}\right)+\ln \left(c_{t}\right)\right] d t
$$

The welfare comparisons are shown in figures 7 to 10. Figure 7 shows the welfare costs as a function of the "degree of temporariness", $T$. For the three different policies analyzed and when $\gamma=.75$, the cost goes to zero as $T$ gets very small, increases initially, reaches a maximum and then starts to decrease until eventually turns into a welfare gain at long horizons. When currency substitution is shut down (i.e., $\gamma=1$ ), the pattern changes only in that for large values of $T$ the welfare cost tends to zero. This is related to the fact that in this case the model shows superneutrality to permanent changes in either the money growth rate or the devaluation rate. If the degree of temporariness is interpreted as the degree of lack of credibility, ${ }^{21}$ the figure shows that it is not clear that for low levels of credibility the use of money as a nominal anchor is preferred to the nominal exchange rate, as might be interpreted from Calvo and Végh (1993b), pages 21-22. In the experiment displayed in figure 7. the ERB program is less costly than the money based program even for low values of $T$ regardless of the presence of currency substitution. On the other hand the MBR program does better than the ERB program in cases of very low credibility.

In figure $S$ the welfare costs are computed for different values of the long-run (and prestabilization value of the) inflation rate, $\epsilon^{H}$. Under currency substitution, the costs associated with ERB and MB programs are non-monotonic in $e^{H}$. Two forces going in opposite directions are responsible for this. On the one hand, temporary changes in the nominal interest rate perturb the consumption paths from being constant, and thus are costly for agents with concave instant utility functions. On the other hand, there is a positive welfare effect associated with the substitution of domestic for foreign currency even when the devaluation rate is reduced temporarily. In the $\mathrm{MB}$ program, the first effect dominates right from the beginning for the parameter values chosen. To disentangle these two effects, panel (b) of figure 8 shows the same computations for a single-currency economy, $\gamma=1 .{ }^{22}$ In this case,

\footnotetext{
${ }^{21}$ These two concepts are strictly equivalent only in the case in which the elasticity of currency substitution is zero. In this case permanent unexpected changes in either the devaluation rate or the money growth rate have no effects on real variables such as consumption, the real exchange rate and the domestic real interest rate. So if at $t=T$ the public learns that the stabilization program is there to stay, the paths of real variables remain unperturbed. In the presence of currency substitution, however, permanent changes in the money growth rate or in the devaluation rate will affect the long-run level of consumption of tradables because of the wealth effect associated with the substitution of currencies, so temporariness and lack of credibility are not equivalent.

${ }^{22}$ similar results are obtained if the degree of substitutability is driven to zero by setting the parameter $\rho$ very large.
} 
the welfare cost of ERB programs is always decreasing in the long-run inflation rate. Since the $\mathrm{MB}$ and the MBR programs display identical dynamics for the consumption of tradables, all the difference in welfare costs between these two programs stems from the behavior of the consumption of home goods. Under currency substitution, the MBR programs avoids the initial recession in this market and in the single-currency economy it generates a boom. This translates in lower welfare costs when the economy is reliquefied on impact.

Figure 9 shows the welfare costs for different values of the elasticity of currency substitution, $(1+\rho)^{-1}$. As this elasticity increases, the welfare costs are always decreasing for the ERB program, initially decreasing for the MBR program, and always increasing for the MB program. The reason for this pattern is that the higher is $(1 \rho)^{-1}$, the stronger is the welfare effect associated with the substitution of currencies in response to a temporary reduction in inflation. In the MB program, however, a higher elasticity of currency substitution induces a stronger initial deflation and recession in the home-good market, because, given the money supply, that is the only way by which the increase in domestic-money demand can be materialized. The initial reliquefication prevents the deflation from happening and thus does better than the MB program.

Figure 10 shows the cost of temporary stabilization programs as a function of the parameter $\theta$, that relates the speed of adjustment of the inflation rate as a fraction, $\theta$, of the "unemployment rate" in the home-good market. These costs associated with temporary seem to be very sensitive to changes in $\theta$, and are always decreasing in it. This is not surprising if one remembers that a low value of $\theta$ means that either firms do not revise their prices very frequently, or that when they do, the price changes do not respond much to the degree of excess demand, or both. Figure 11, clarifies this point by showing the dynamics of inflation and consumption of home-goods for two values of $\theta, .04$ and $.4 .^{23}$ The inflation rate takes a longer time to catch-up with the devaluation rate when $\theta$ is small. Consequently, the real exchange rate (not shown in the figure) appreciates much more in the ERB and MBR programs and the initial appreciation takes much longer to disappear in the MB program. This, in turn, translates in an amplification of the eventual recession in the ERB and MBR. programs, and in a longer and more pronounced initial recession in the MB program.

\footnotetext{
${ }^{23}$ Recall that the behavior of consumption of tradables is independent of $\theta$ due to the functional form assumed for preferences.
} 


\section{Conclusions}

The welfare comparisons performed above suggest that exchange-rate based programs and money based programs with initial reliquefication are less costly than money based programs, even at low levels of credibility and low degrees of currency substitution. This might explain in part why pure money based stabilization episodes are so infrequent.

Exchange-rate based and money based programs with initial reliquefication produce similar welfare costs, except in two cases: at low levels of credibility (or high degrees of temporariness), money based programs with initial reliquefication do better, while for high elasticities of currency substitution exchange-rate based programs appear to be less costly.

There are at least two reasons for why, although frequently advocated, money based programs with initial reliquefication are seldom observed. First, in the very short-run money based programs with initial reliquefication are observationally equivalent to exchange-rate based programs and hence it is conceivable that episodes that fall into the category of money based programs with reliquefication are actually labeled exchange-rate based program. Second. from a reputational standpoint, it might be difficult for policy makers to announce a program that limits the rate of money growth and at the same time implement a once-andfor-all increase the stock of money. From this perspective it might be easier to implement an exchange-rate based program and convince the public that under such regime the central bank has no control over the stock of money, and that any increase in it reflects an increase in the public's demand for real balances.

The speed at which inflation adjusts to its long-run level measured in the model by the parameter $\theta$, is an important determinant of the welfare cost for all of the policies studied. Low values of $\theta$ are associated with high welfare costs because the inflation rate takes longer to converge to the devaluation rate, amplifying the degree of real exchange rate appreciation and the recession in the home-good market.

It is worth recalling that all the computations performed in this paper were constrained to the case of logarithmic and additively separable instantaneous utility functions. Specifically, the analysis ignores the effects of varying the degree of intertemporal substitution in consumption. This omission is particularly important for two reasons: first, most of the real effects in the model used above come from intertemporal substitution induced by a temporary reduction in inflation, which in the model acts as a tax on purchases of goods through the cash-in-advance constraint. Second, empirical estimates of the intertemporal elasticity of substitution (Giovannini, 1985; and Reinhart and Végh, 1993) suggest values of arou $\lambda_{2} .2$ for developing countries, way below unity. In general, it would be important to perform the welfare comparisons using calibrated versions of the model in order to obtain quantitative 
values for the costs of engaging in each of the different inflation stabilization strategies. This task is left for future research. 


\section{References}

Boyce, William E. and DiPrima, Richard C., Elementary Differential Equations and Boundary Value Problems, (1965), N. York, J. Wiley.

Calvo, Guillermo A., "Staggered Prices in a Utility-Maximizing Framework," Journal of Monetary Economics, 1983, 12, pp. 383-98.

Calvo, Guillermo A. and Végh, Carlos A., "Credibility and the Dynamics of Stabilization Policy: A Basic Framework," IMF (1990) WP \#90/110, also in Christopher Sims editor, Advances in Econometrics. Sixth World Congress, Cambridge University Press.

Calvo, Guillermo A. and Carlos A. Végh, "Inflation Stabilization and Nominal Anchors," mimeo, 1993a.

Calvo, Guillermo A. and Carlos A. Végh, "Exchange Rate Based Stabilization Under Imperfect Credibility," in Helmut Frisch and Andreas Worgotter Eds., Open Economy Macroeconomics, London MacMillan Press, 1993b, Chapter 1, pp. 3-28.

Giovannini, Alberto. "Savings and the Real Interest Rate in LDC's," Journal of Development Economics. 1985. 17 pp 197-217.

Kiguel. Miguel A. and Liviatan, Nissan, "The Business Cycle Associated with ExchangeRate Based Stabilizations." The World Bank Economic Review, 1992a, 6 pp 279-305.

Kiguel, Miguel A. and Liviatan. Nissan, "Stopping Three Big Inflations," mimeo, World Bank. 1992b

Reinhart Carmen .M. and Végh. Carlos A., "Intertemporal Consumption Substitution and Inflation Stabilization: An Empirical Investigation," mimeo IMF, January 1993.

Végh. Carlos A., "Stopping High Inflation: An Analytical Overview," IMF Staff Papers, September 1992. 39:3 pp 626-695. 
Table 1:

Parameter values used in the simulations

\begin{tabular}{|l|c|l|}
\hline Parameter & Value & Description \\
\hline$\gamma$ & 0.5 & fraction of GNP subject to cash constraint \\
$\theta(1+\rho)^{-1}$ & 1.0 & elasticity of currency substitution \\
\hline$T$ & 0.4 & speed of adjustment of inflation \\
$r$ & 10 & duration of the program (quarters) \\
$\epsilon^{H}=\mu^{H}$ & $10 \%$ & long-run devaluation and money growth rates \\
$\epsilon^{L}=\mu^{L}$ & $1.0 \%$ & devaluation and money growth rates during the transition \\
$y^{p}$ & 1.0 & $\begin{array}{l}\text { permanent (traded) income } \\
\bar{y}\end{array}$ \\
\hline
\end{tabular}


Figure 1: Exchange-Rate Based Stabilization: A Single-Currency Economy

Transition period: 10 quarters

Long run devaluaton rate: $10 \%$

Devaluation rate during transition: $1 \%$

Real interest rate: $1.5 \%$
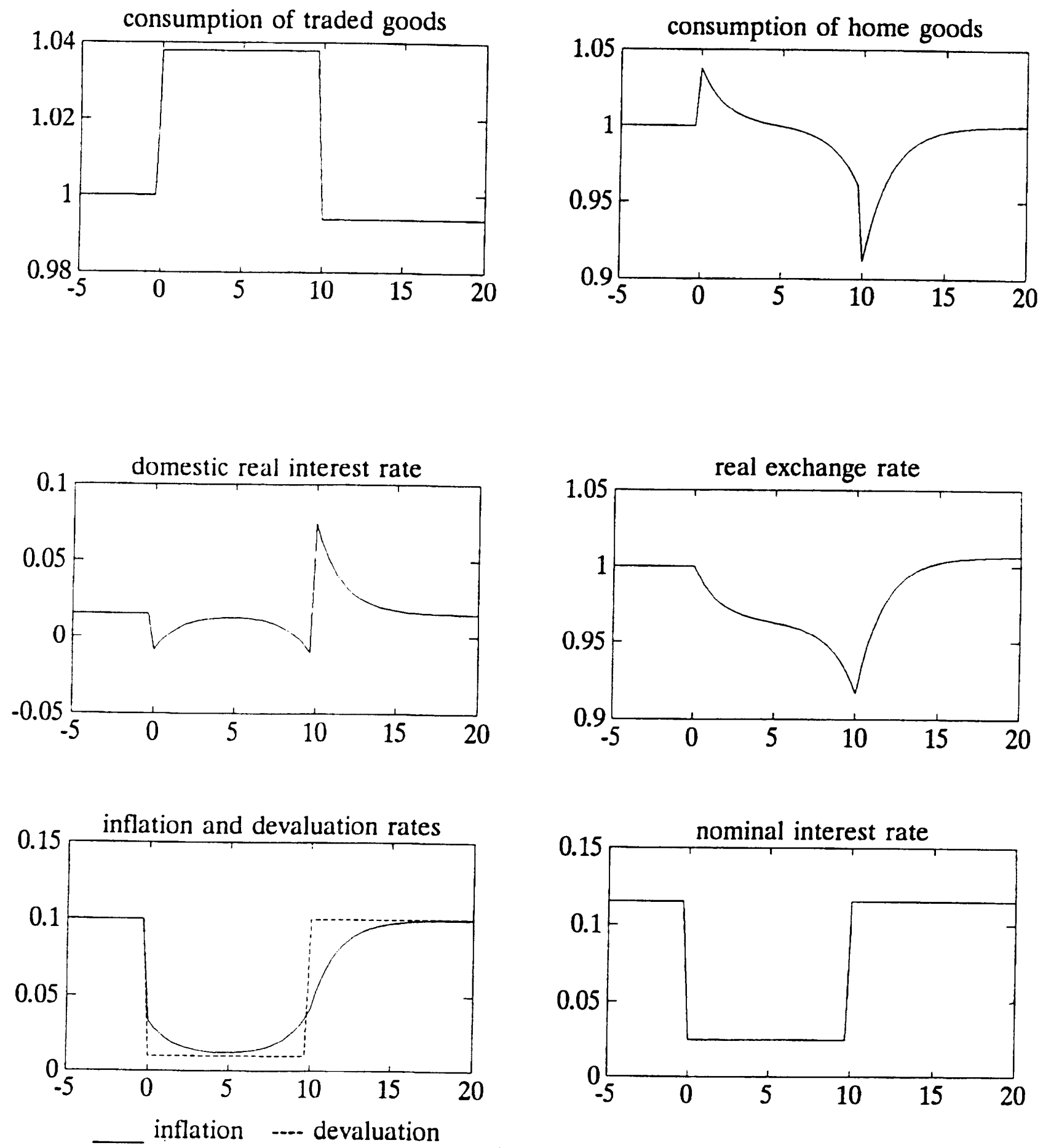
Figure 2: Exchange-Rate Based Stabilization Under Currency Substitution

The Dynamics of Consumption of Tradables and Real Balances for Different Values of the Elasticity of Substitution Between Domestic and Foreign Currencies, 1/(1+rho)
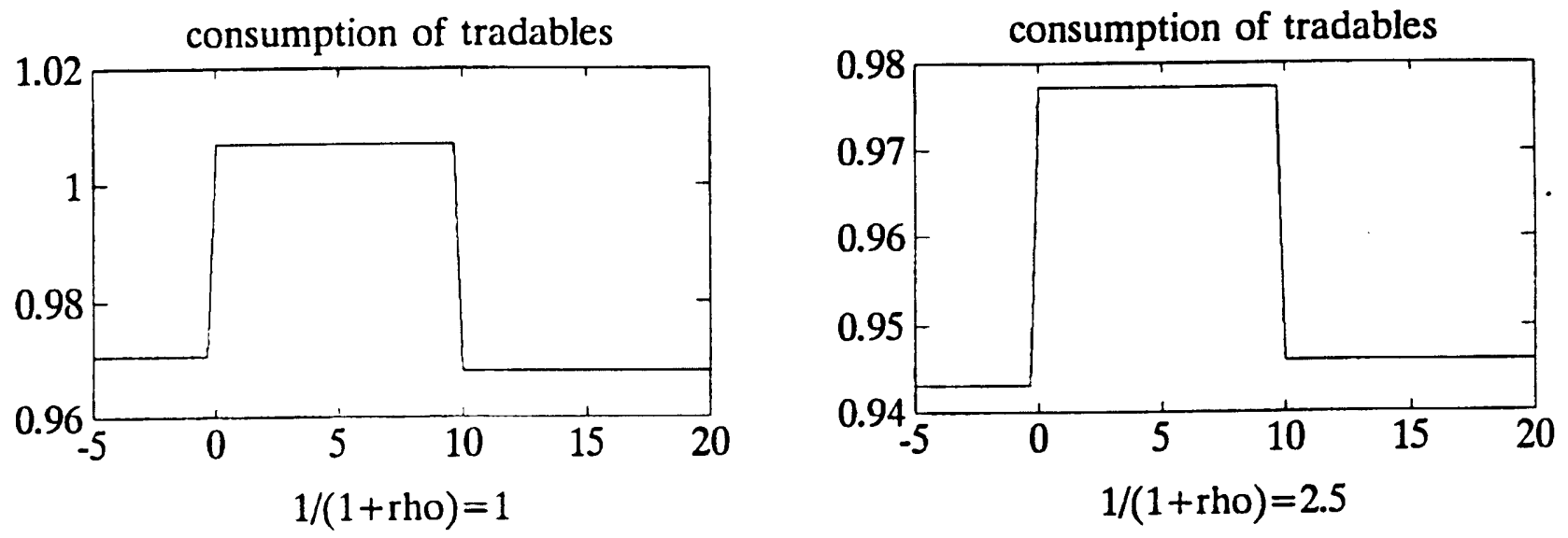

Domestic-to-Foreign-Currency Ratio

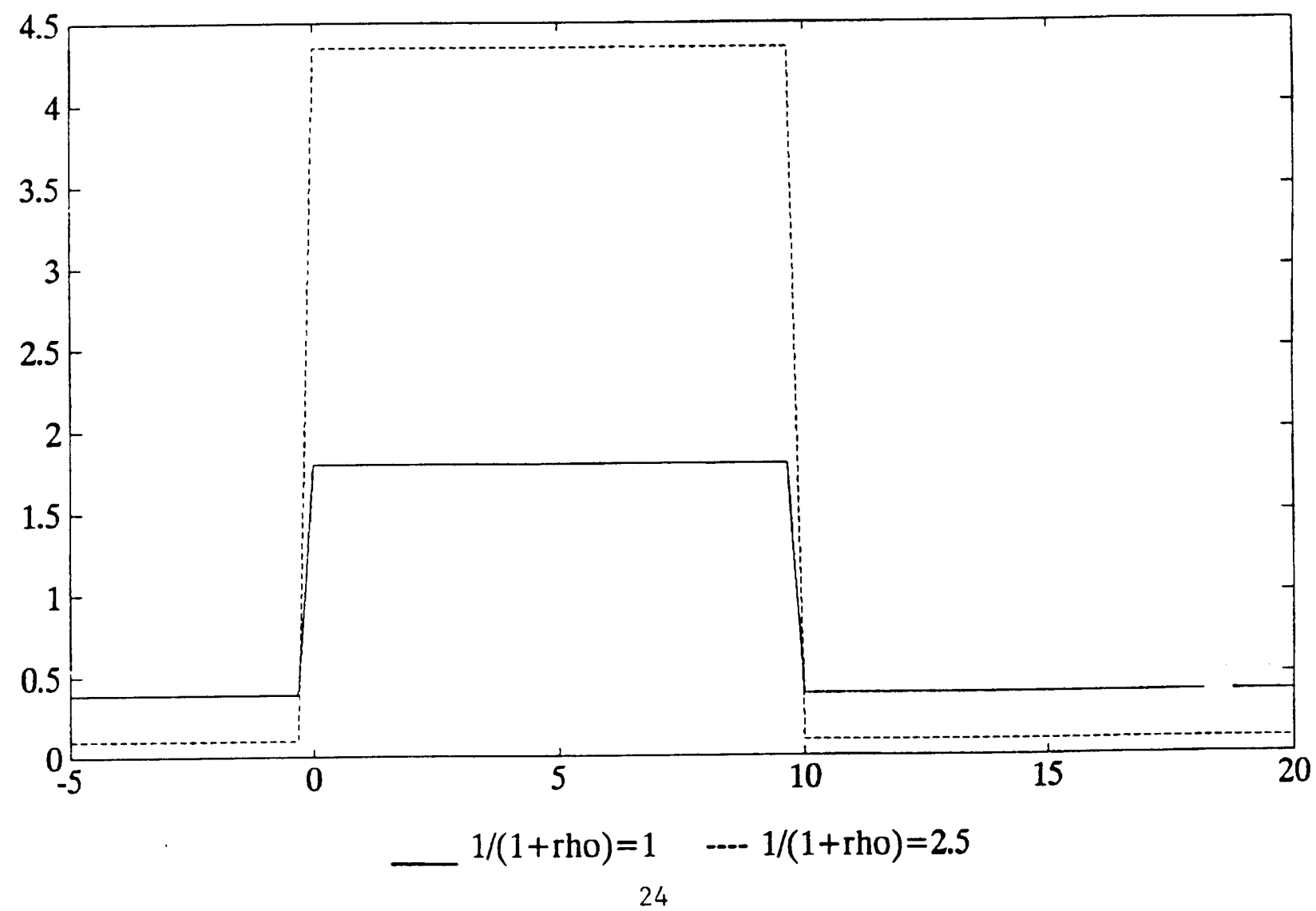


Figure 3: Comparing Money and Exchange-Rate Based Stabilization A Single-Currency Economy

\section{Money Based Stabiliaztion \\ ------ Exchange-Rate Based Stabilization}

See also headings on figures 1 and 2
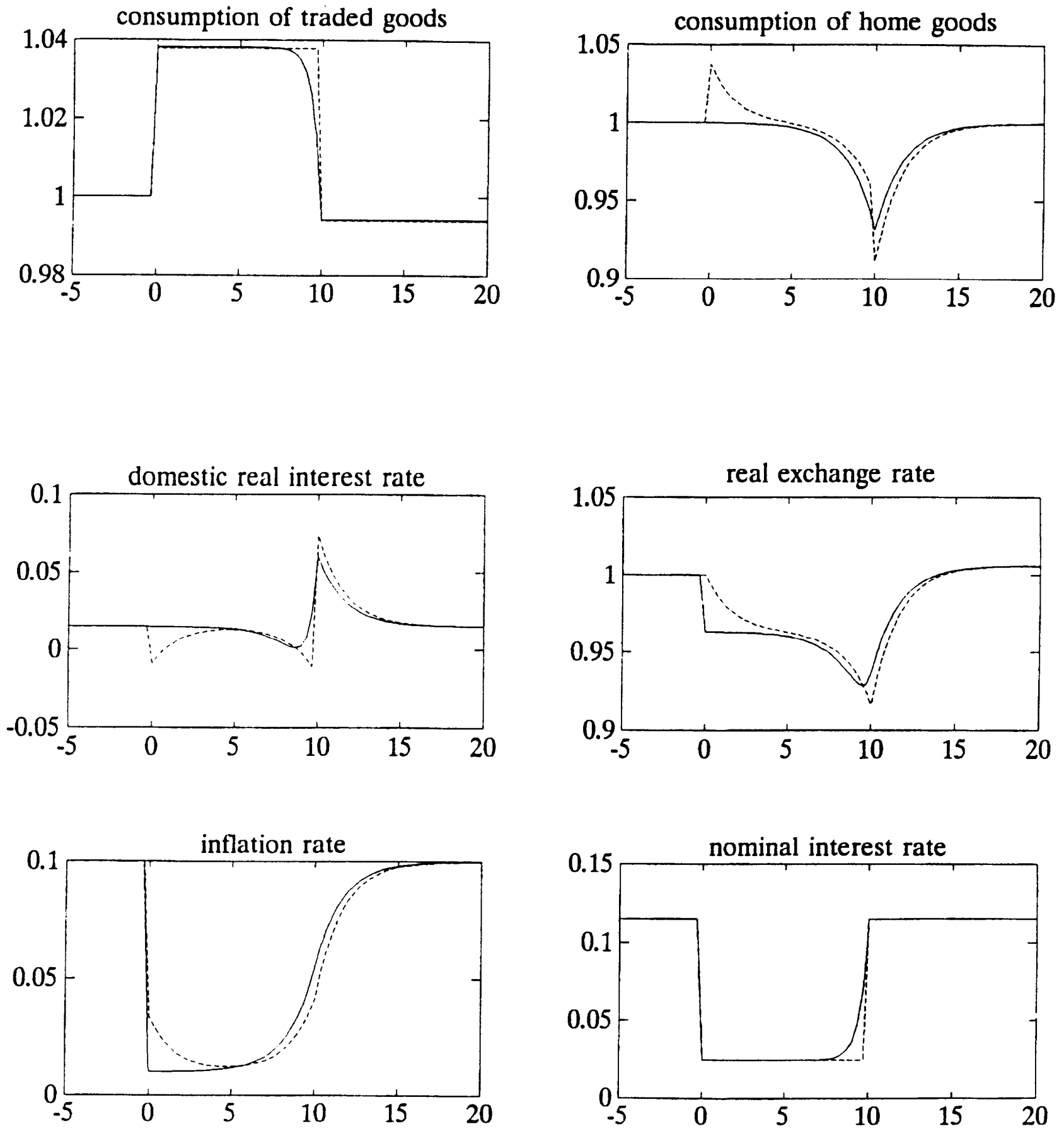
Figure 4: Comparing Money and Exchange-Rate Based Stabilization Under Currency Substitution

\section{Money Based Stabiliaztion \\ --.-- Exchange-Rate Based Stabilization}

See also headings on figures 1 and 2
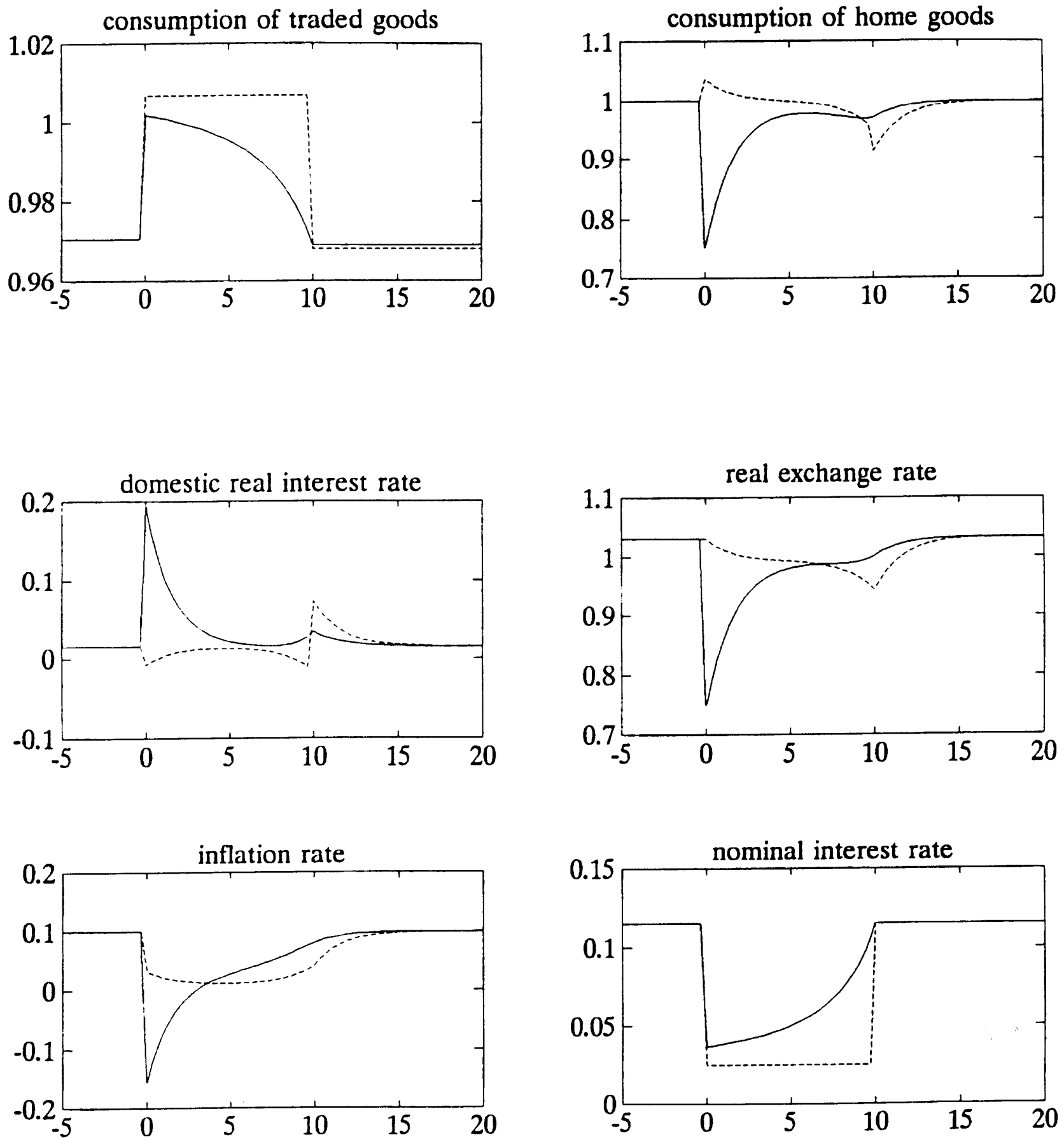
Figure 5: Reliquefication in a Single Currency Economy

Money Based Stabiliaztion
...... Exchange-Rate Based Stabilization
...x...x Money Based with Initial RELIQUEFICATION

See also headings on figures 1 and 2
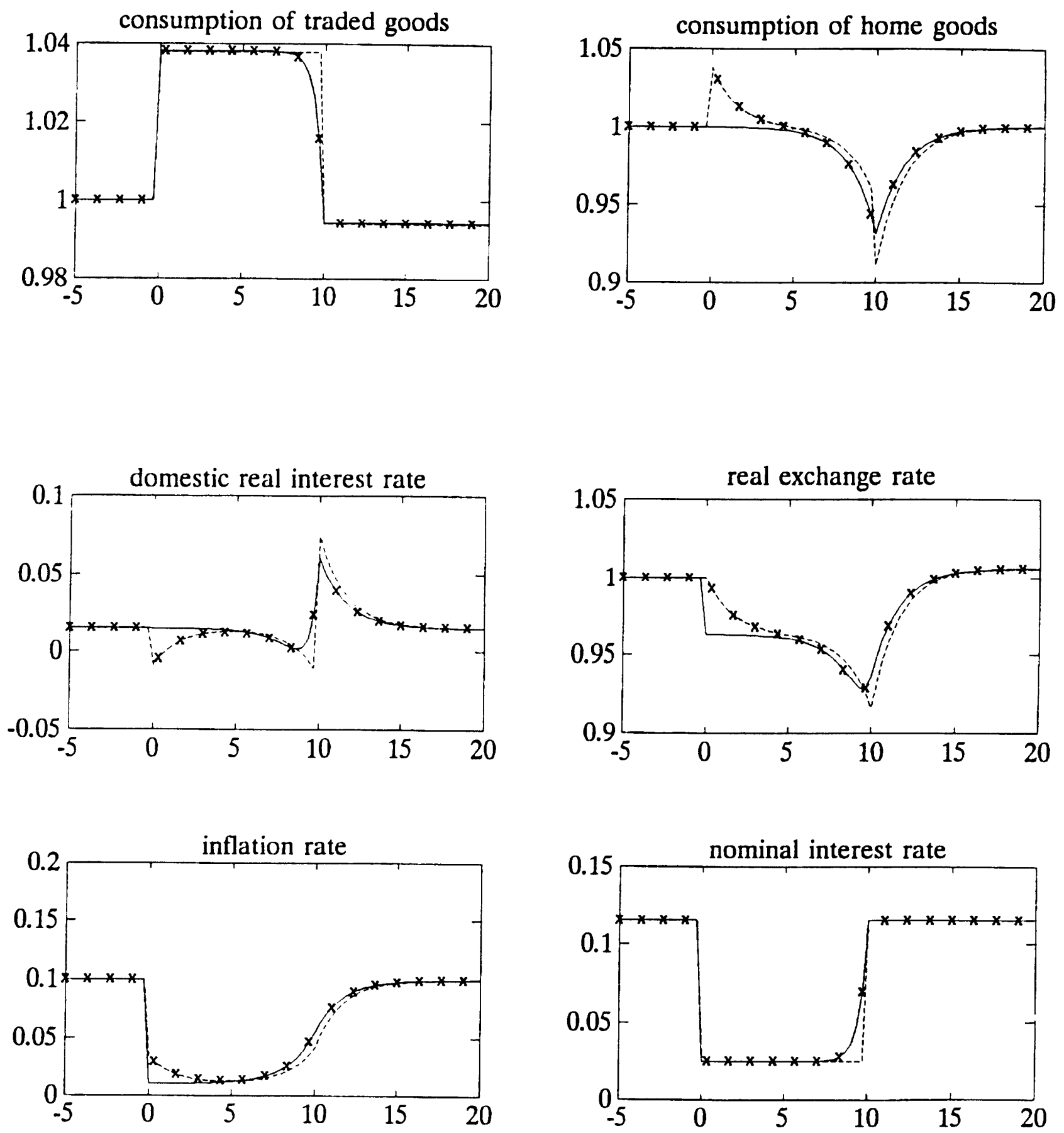
Figure 6: Reliquefication Under Currency Substitution

Money Based Stabiliaztion

------ Exchange-Rate Based Stabilization

...x...x Money Based with Initial RELIQUEFICATION

See also headings on figures 1 and 2
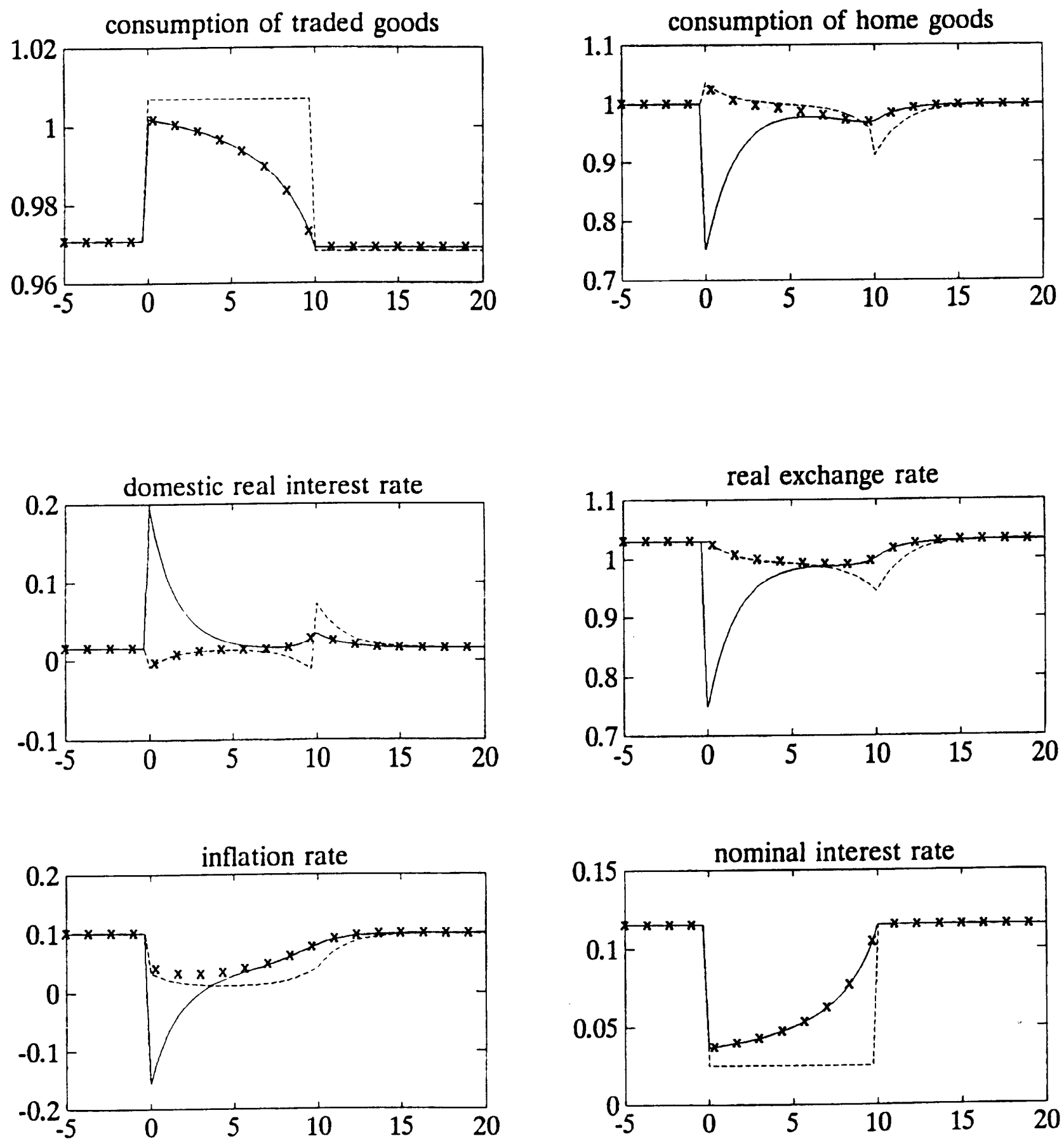
Figure 7 (a): Welfare Costs as a Function of T. $\gamma=.75$

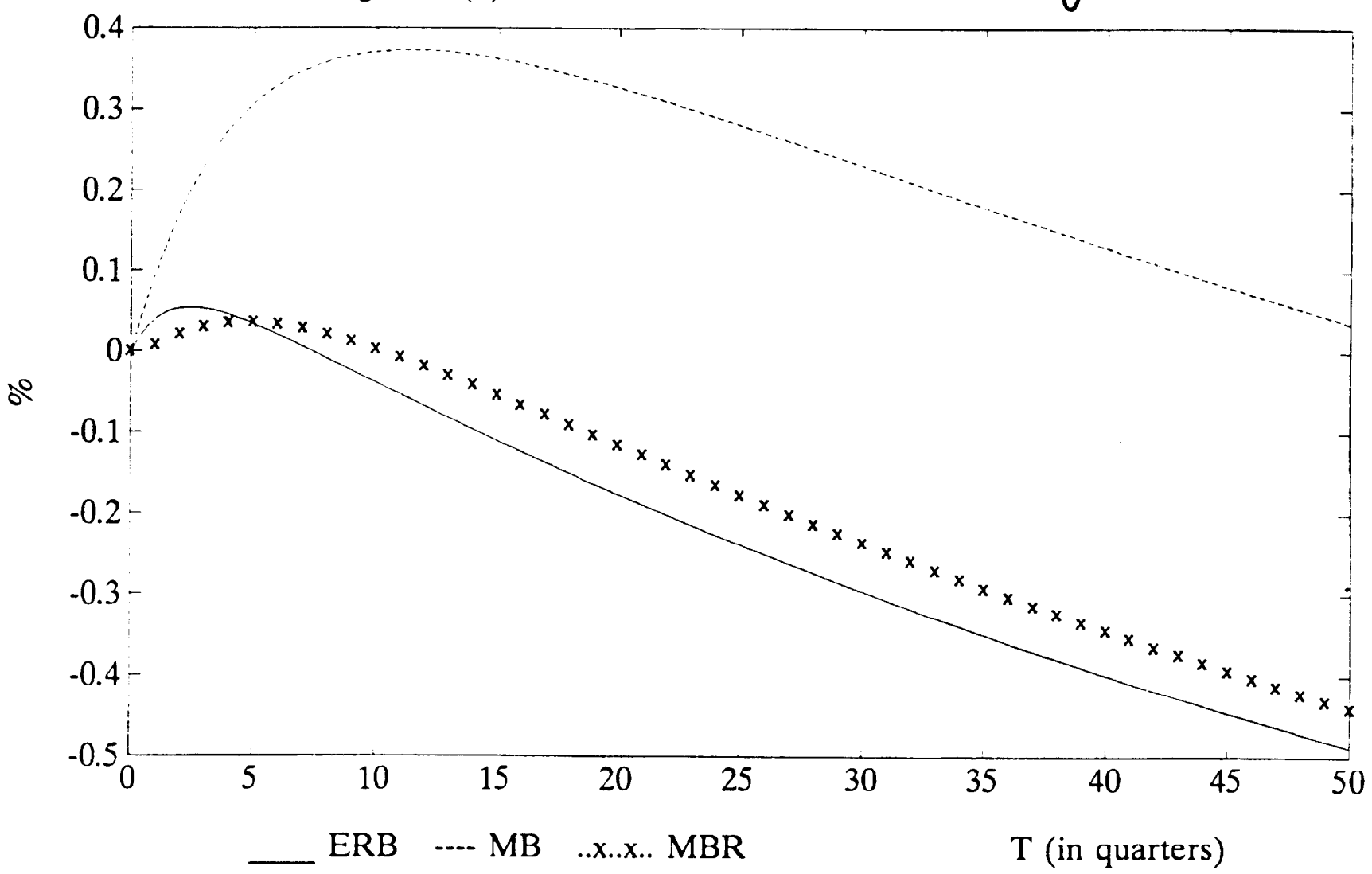

Figure 7 (b): Welfare Costs as a Function of T. $\gamma=1$

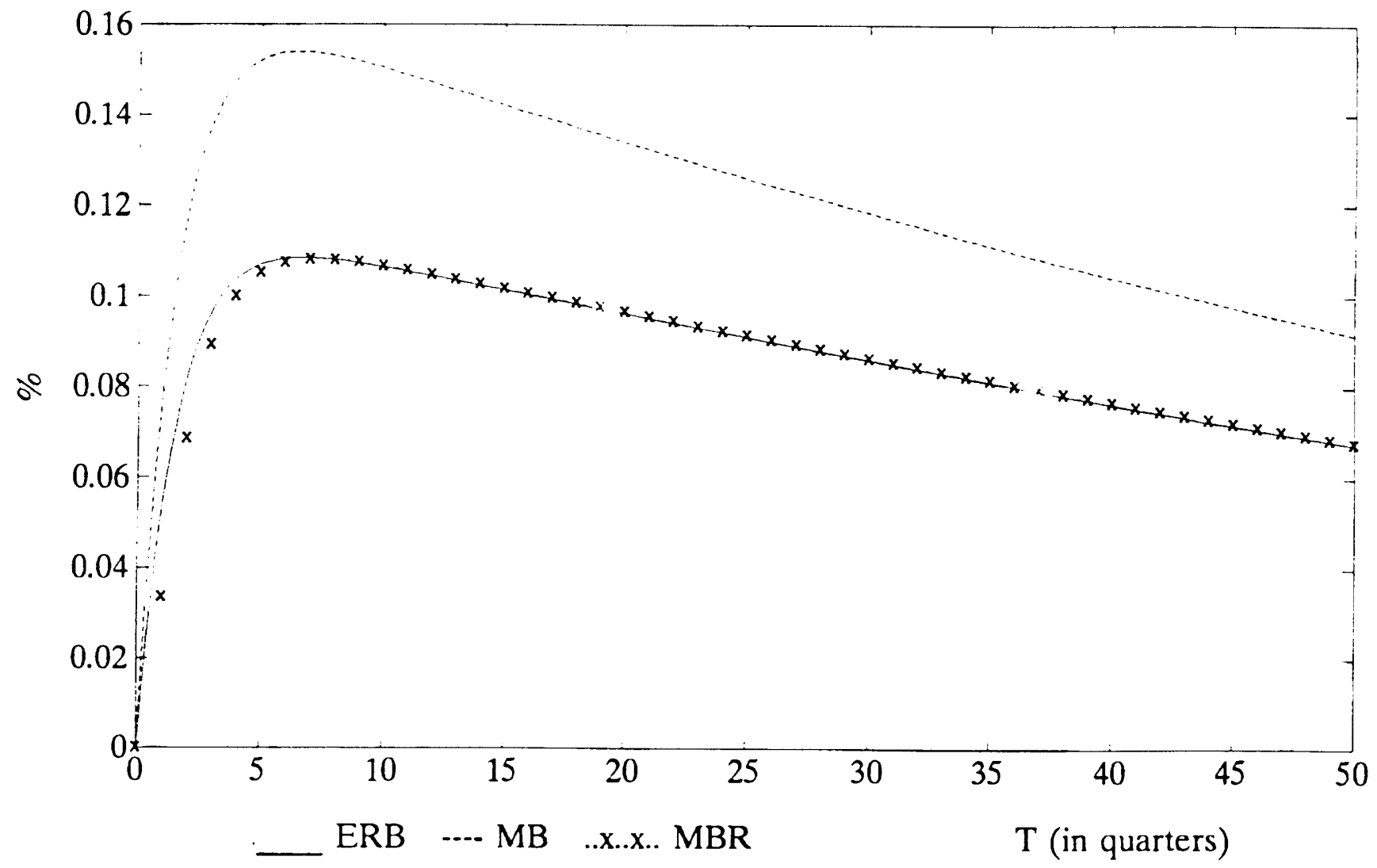




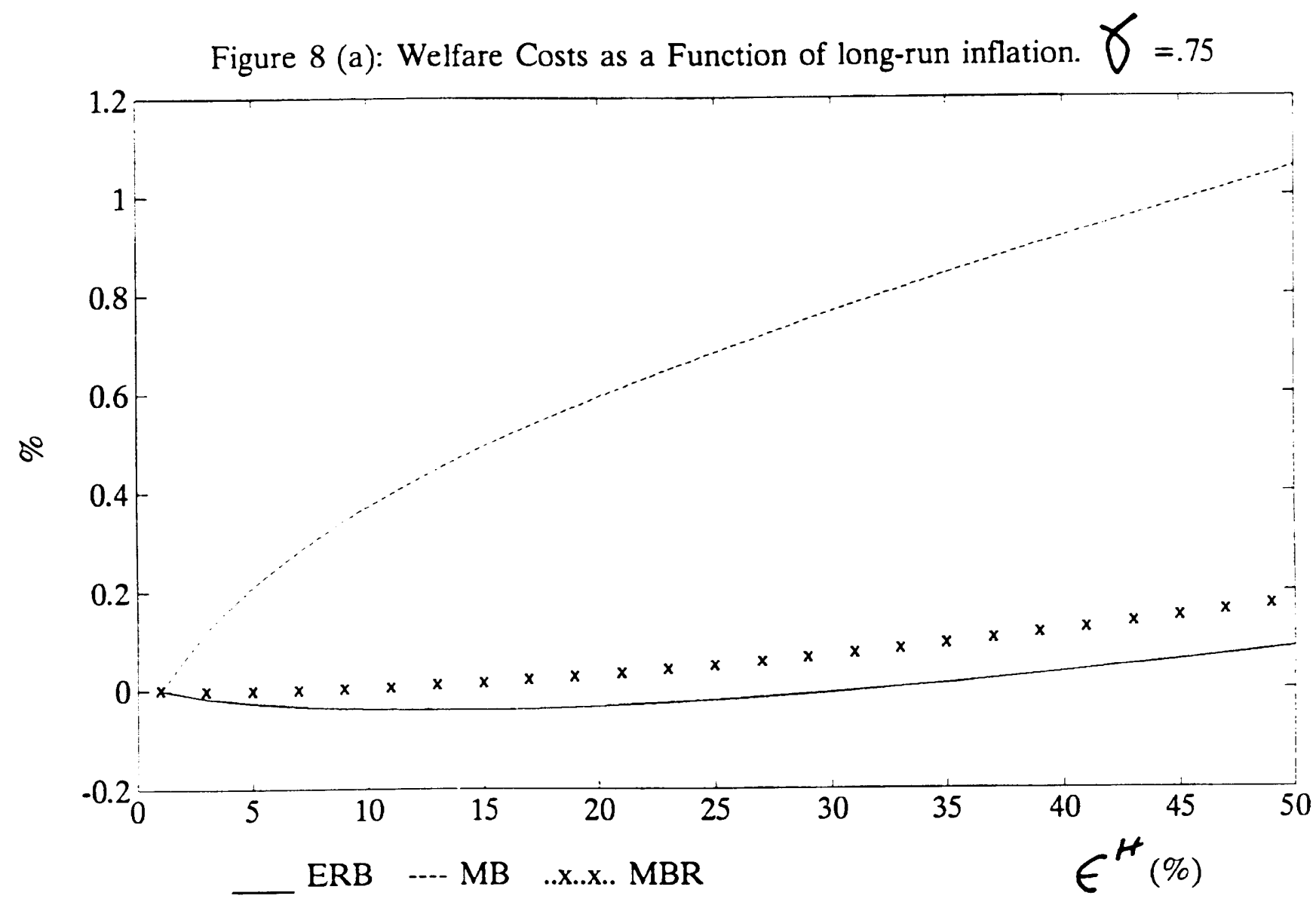

Figure 8 (b): Welfare costs as a Function long-run inflation. $\gamma=1$

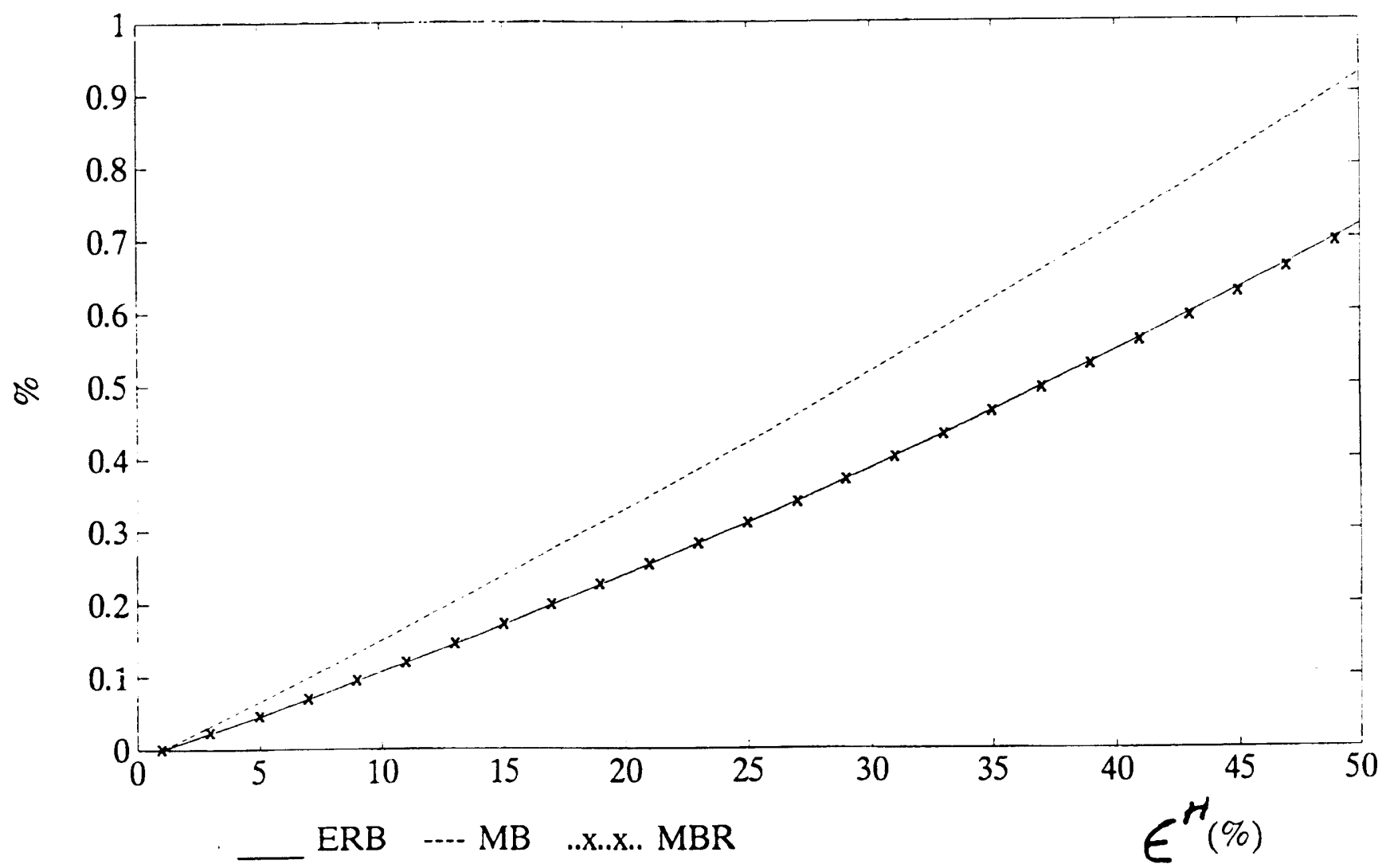


Figure 9: Welfare Costs as a Function of the elasticity of currency substitution. $\gamma=.75$

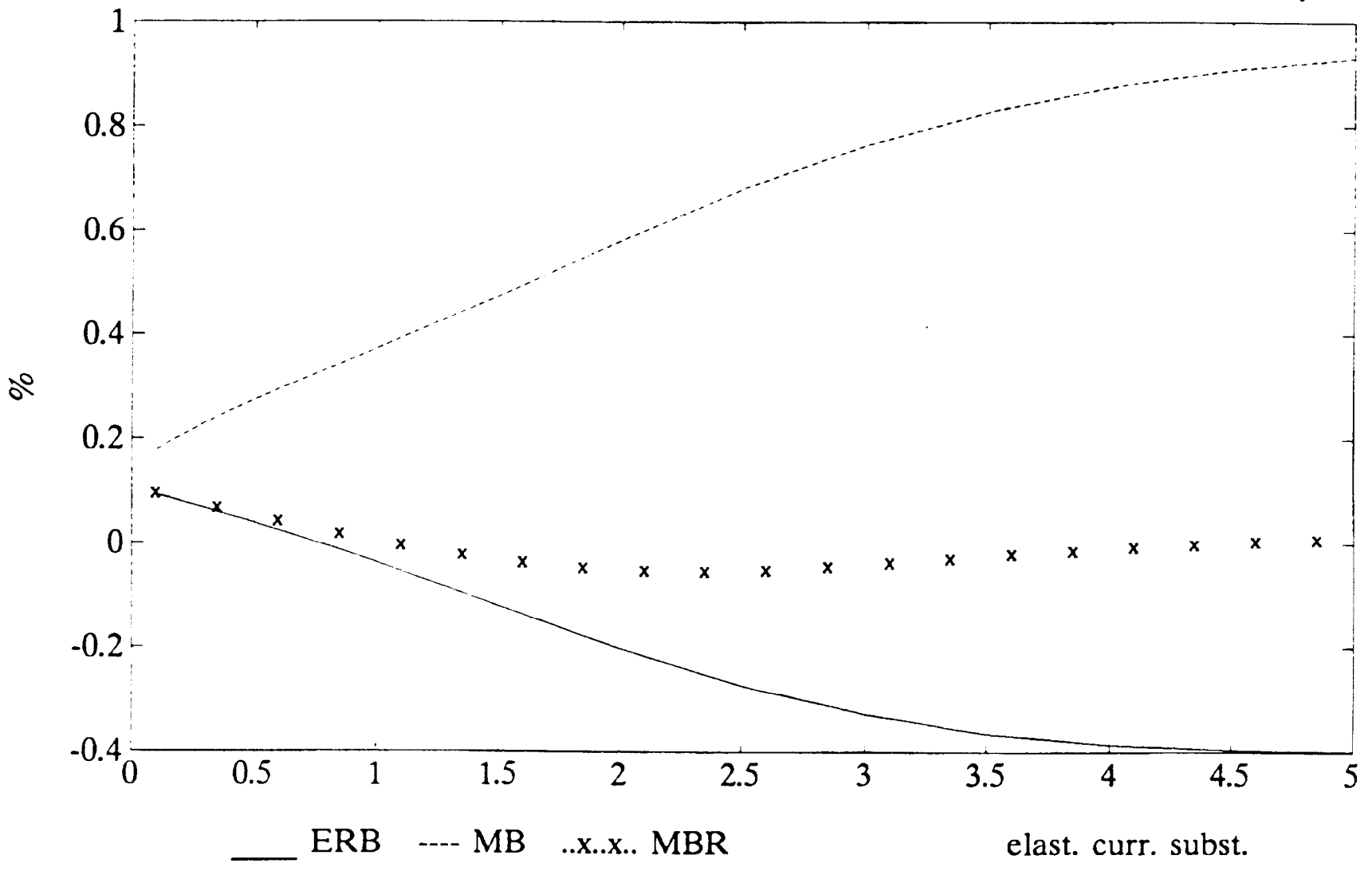


Figure 10 (a): Welfare Costs as a Function of $\theta .=.75$

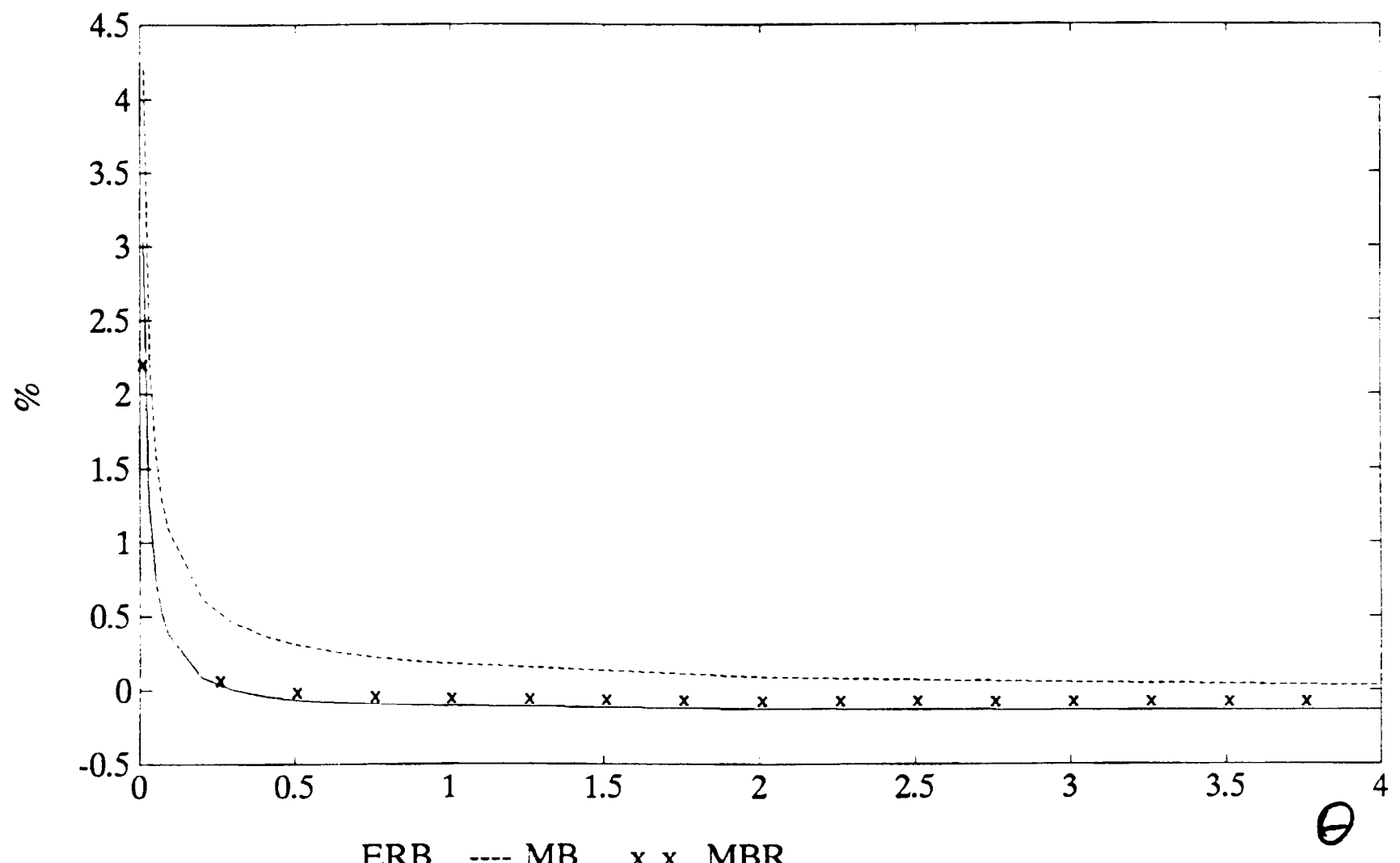

Figure $10(\mathrm{~b})$ : Welfare Costs as a Function of $\boldsymbol{\theta} . \quad=1$

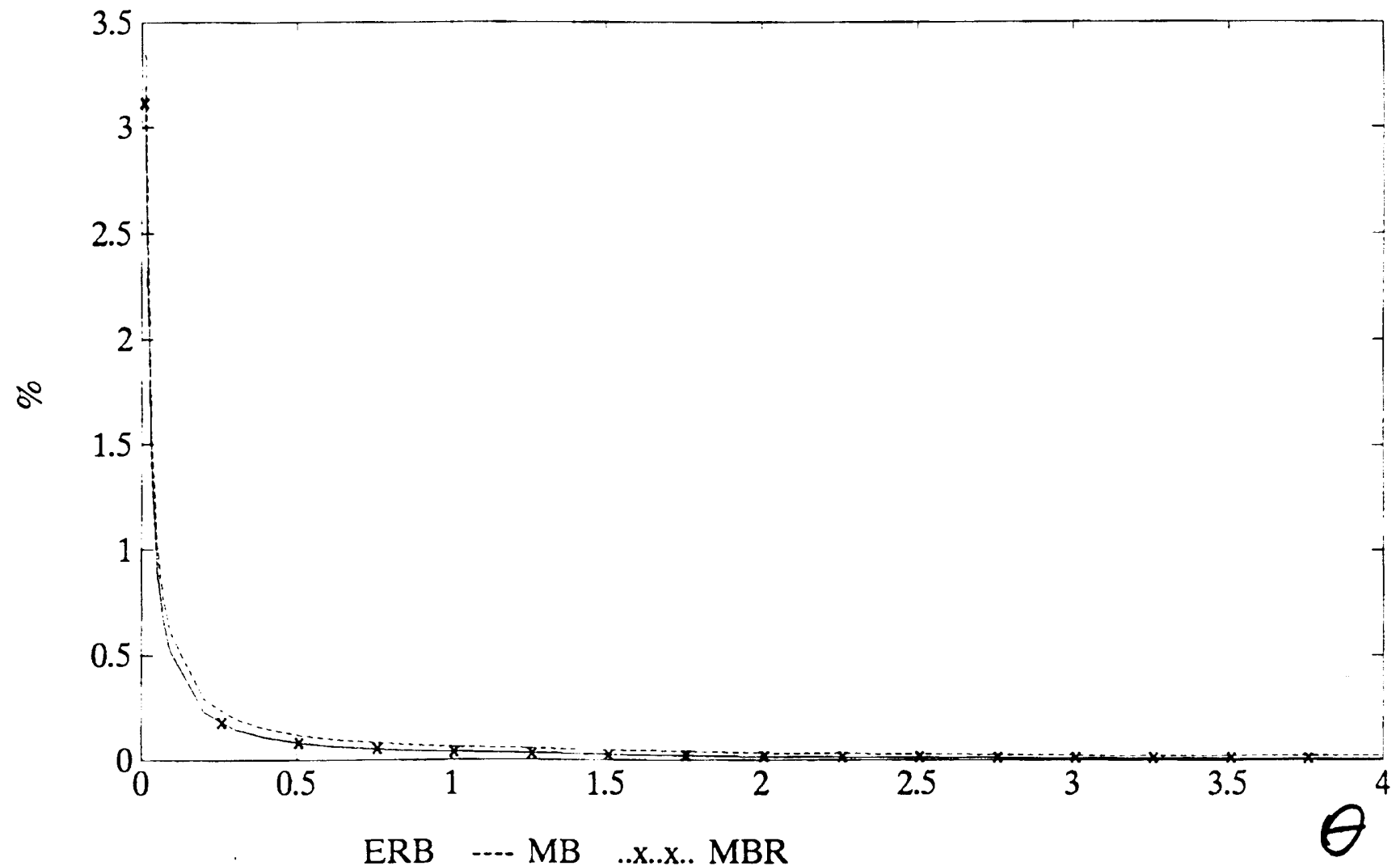


Figure 11: Inflation and Consumption of Horne Goods as a Function of theta

$E R B=$ Exchange-Rate Based Program

$\mathrm{MB}=$ Money Based Program

MBR Money Based with Initial Reliquefication
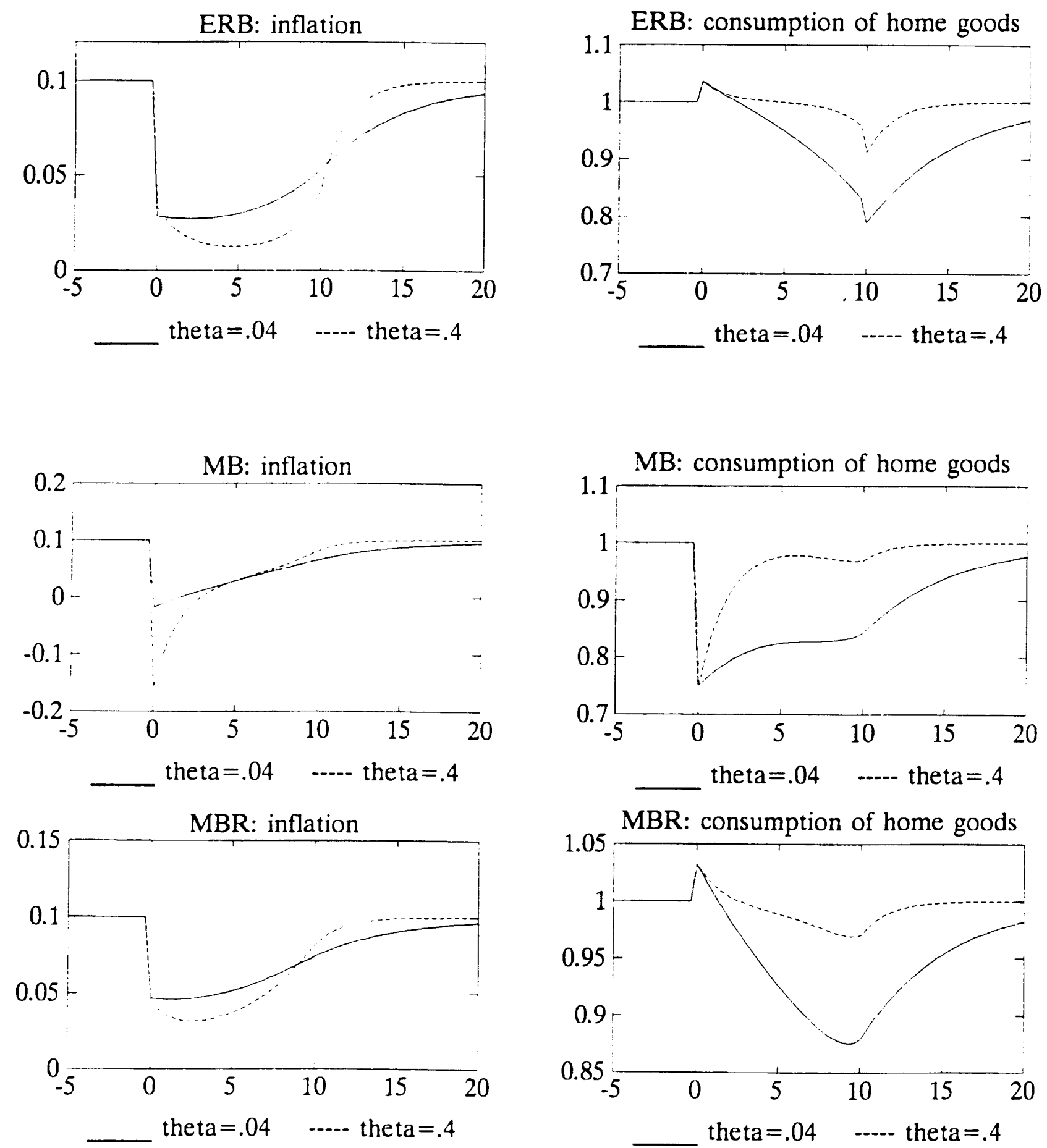


\section{International Finance Discussion Papers}

IFDP

Number

Titles

Author(s)

1996

539 Comparing the Welfare Costs and the Initial Dynamics

of Alternative Temporary Stabilization Policies

538 Long Memory in Inflation Expectations: Evidence from International Financial Markets

537 Using Measures of Expectations to Identify the Effects of a Monetary Policy Shock

Allan D. Brunner

$536 \quad$ Regime Switching in the Dynamic Relationship between the Federal Funds Rate and Innovations in Nonborrowed Reserves

535 The Risks and Implications of External Financial Shocks: Lessons from Mexico

Martin Uribe

Joseph E. Gagnon

Chan Huh

Edwin M. Truman

Jeffrey A. Frankel

Currency Crashes in Emerging Markets: An

Empirical Treatment

Andrew K. Rose

Charles Engel

Regional Patterns in the Law of One Price:

The Roles of Geography vs. Currencies

John H. Rogers

1995

532 Aggregate Productivity and the Productivity of Aggregates

Susanto Basu

John G. Fernald

531 A Century of Trade Elasticities for Canada, Japan, and the United States

Jaime Marquez

$530 \quad$ Modelling Inflation in Australia

Gordon de Brouwer

Neil R. Ericsson

529 Hyperinflation and Stabilisation: Cagan

Marcus Miller

Revisited

Lei Zhang

528 On the Inverse of the Covariance Matrix in

Portfolio Analysis

Guy V.G. Stevens

527 International Comparisons of the Levels of Unit

Labor Costs in Manufacturing

Peter Hooper

Elizabeth Vrankovich

Please address requests for copies to International Finance Discussion Papers, Division of International Finance, Stop 24, Board of Governors of the Federal Reserve System, Washington, DC 20551. 


\section{International Finance Discussion Papers}

IFDP

Number
Titles

1995

526 Uncertainty, Instrument Choice, and the Uniqueness of Nash Equilibrium: Microeconomic and Macroeconomic Examples

525 Targeting Inflation in the 1990s: Recent Challenges

524 Economic Development and Intergenerational Economic Mobility

523 Human Capital Accumulation, Fertility and Growth: A Re-Analysis

522 Excess Returns and Risk at the Long End of the Treasury Market: An EGARCH-M Approach

521 The Money Transmission Mechanism in Mexico

520 When is Monetary Policy Effective?

519 Central Bank Independence, Inflation and Growth in Transition Economies

518 Alternative Approaches to Real Exchange Rates and Real Interest Rates: Three Up and Three Down

517 Product market competition and the impact of price uncertainty on investment: some evidence from U.S. manufacturing industries

$516 \quad$ Block Distributed Methods for Solving Multi-country Econometric Models

515 Supply-side sources of inflation: evidence from OECD countries

514 Capital Flight from the Countries in Transition: Some Theory and Empirical Evidence

513 Bank Lending and Economic Activity in Japan: Did "Financial Factors" Contribute to the Recent Downturn?
Author(s)

Dale W. Henderson

Ning S. Zhu

Richard T. Freeman Jonathan L. Willis

Murat F. Iyigun

Murat F. Iyigun

Allan D. Brunner

David P. Simon

Martina Copelman

Alejandro M. Werner

John Ammer

Allan D. Brunner

Prakash Loungani

Nathan Sheets

Hali J. Edison

William R. Melick

Vivek Ghosal

Prakash Loungani

Jon Faust

Ralph Tryon

Prakash Loungani

Phillip Swagel

Nathan Sheets

Allan D. Brunner

Steven B. Kamin 